ANONYMOUS MARKET AND GROUP TIES

IN INTERNATIONAL TRADE

\author{
Alessandra Casella \\ James E. Rauch
}

Working Paper 6186 


\title{
ANONYMOUS MARKET AND GROUP TIES \\ IN INTERNATIONAL TRADE
}

\author{
Alessandra Casella \\ James E. Rauch
}

Working Paper 6186

http://www.nber.org/papers/w6186

\author{
NATIONAL BUREAU OF ECONOMIC RESEARCH \\ 1050 Massachusetts Avenue \\ Cambridge, MA 02138 \\ September 1997
}

Our special thanks to Daron Acemoglu, Daniel Cohen, Harl Ryder, and Joel Sobel for their very helpful suggestions. Casella thanks seminar participants at EUI in Florence, Paris, GREQAM in Marseille, Brown, the NBER, Columbia, UCSD, and the CEPR. Financial support was provided by NSF grant \#SBR-9709237 to the National Bureau of Economic Research. This paper is part of NBER's research program in International Trade and Investment. Any opinions expressed are those of the authors and not those of the National Bureau of Economic Research.

(C) 1997 by Alessandra Casella and James E. Rauch. All rights reserved. Short sections of text, not to exceed two paragraphs, may be quoted without explicit permission provided that full credit, including $\mathbb{C}$ notice, is given to the source. 
Anonymous Market and Group Ties in

International Trade

Alessandra Casella and James E. Rauch

NBER Working Paper No. 6186

September 1997

JEL No. F10

International Trade and Investment

\section{$\underline{\text { ABSTRACT }}$}

When trade involves differentiated products, preferential ties to a group settled abroad facilitate an exporter's entry into the foreign market by providing information and access to distribution channels. This contrasts with the difficulties experienced by an unattached producer unfamiliar with the foreign environment. Inspired by the role of coethnic ties and business groups in East Asia, we build a simple general equilibrium model of trade that formalizes this observation. Output is generated through bilateral matching of agents spanning a spectrum of types. Domestic matching is perfect--every trader knows the type of all others and can approach whomever he chooses, but international matching is random--every trader lacks the information to choose his partner's type. However, group ties allow perfect matching abroad to a minority of individuals who have access to them and can decide whether or not to exploit them. We show that in the absence of ties the existence of informational barriers reduces the volume of trade. By increasing trade, group ties are beneficial to the economy as a whole, but have significant distributional effects. On average, group members benefit, but some may lose; non-members lose almost without exception, with the largest losses concentrated among those with the poorest domestic market niches.

\author{
Alessandra Casella \\ Department of Economics \\ Columbia University \\ 420 West 118th Street \\ New York, NY 10027 \\ and NBER \\ ac186@columbia.edu
}

James E. Rauch

Department of Economics

University of California, San Diego

La Jolla, CA 92093

and NBER

jrauch@weber.ucsd.edu 


\section{Introduction}

In this paper we develop a model of trade that reflects the difficulty of placing one's product in its correct international market niche. Access to a group that provides preferential information about the foreign market facilitates this placement. In our set-up, a minority of individuals is provided with the option of using this channel, reflecting for example the existence of coethnic ties or membership in a business group. Using this simple framework, we analyze the aggregate volume of trade without ties, the use of ties versus the anonymous market by group members, the value of the ties to the overall economy and to the group, and the consequences of the ties for non-members.

The economic boom in Southeast Asia has called attention to the role of coethnic ties in international trade and investment (see, e.g., Redding 1995). Studies show that not only the Overseas Chinese but also many other ethnic groups living outside their countries of origin create formal or informal "societies" to which coethnic businesspeople from both the host countries and the mother country have access. Kotkin (1992) states that "Chinese entrepreneurs remain, in essence, arbitrageurs, their widespread dispersion a critical means of identifying prime business opportunities" (p. 169) and "most of Hong Kong's Indian businesses--from the tiny two-man operation to the giant conglomerate--fit the classical mold, with extended families providing the linkages between various national markets" (p. 219). ${ }^{1}$

The operation and economic importance of coethnic societies has been especially well documented for the special case of trade between countries hosting recent immigrants and these

\footnotetext{
${ }^{1}$ Rauch (1996) studies a formal society of English-speaking Caribbean-American businesspeople. Unfortunately, the reasons why some ethnic groups form successful societies and others do not are still a mystery.
} 
immigrants' countries of origin. Gould (1994) finds that immigration to the United States increases U. S. bilateral trade with the immigrants' countries of origin and that this "immigrantlink effect" is stronger for U. S. exports than for U.S. imports, indicating that the effect works primarily through the establishment of business contacts rather than through increased U. S. preferences for goods produced in the country of origin. Chin, Yoon , and Smith (1996, p. 498) give an example of how these business contacts worked to promote Korean wig exports to the United States: ${ }^{2}$

Korean wig importers' contribution to the Korean wig import business was far greater than their numbers. From these immigrant wig importers, South Korea wig manufacturers could obtain information on new styles and market trends. Since they were not able to develop new styles of their own (prominent U.S. hair designers continuously developed innovative styles), South Korean wig manufacturers had to depend entirely on Korean immigrant wig importers for information on trends in U.S. wig fashion.

As a second example of the type of mechanisms we have in mind, consider the role played in international transactions by business groups. Business groups are "sets of firms that are integrated neither completely nor barely at all" (Granovetter 1994, p. 455), and where the lineages of the members can often be traced back to a founding family or small number of allied families. Typical mechanisms serving to integrate the firms include mutual stockholdings and frequent meetings of top executives. ${ }^{3}$ Recent research (see, e.g., Dobson and Chia 1997) has found that business groups that have expanded outside their mother countries play a role similar to coethnic ties in facilitating international transactions. Member firms operating abroad have been found to

\footnotetext{
${ }^{2}$ Wigs were one of the major items in Korea's initial drive to break into world markets for manufactures in the $1960 \mathrm{~s}$ and early 1970s. They were her third largest export item in 1970, accounting for 11.2 percent of total exports.

business groups are common throughout Asia, continental Europe, and Latin America, but are rare to non-existent in Great Britain and the United States.
} 
preferentially trade intermediate goods (in particular) with domestic group members. The best documented cases are of Japanese keiretsu operating in the United States and in Southeast Asia.

Although in this paper we draw inspiration from these two examples, we think they should be seen as only the most empirically visible representatives of a much longer list of preferential networks.

The empirical success of the East Asian coethnic societies and business groups highlights the shortcoming of the assumption of perfect information embedded in the standard approach to trade in differentiated products (e.g., Helpman and Krugman 1985). It is reasonable to imagine that within a country buyers are informed at nominal cost of all available varieties and their characteristics, and sellers are well aware of how to reach the buyers that form their particular market niches. We argue that these presumptions are much less plausible for the international market, where buying agents for consumer goods distributors and firms seeking inputs to production processes incur considerable costs in discovering the foreign varieties available and their characteristics, as well as the capabilities of the suppliers of these varieties, and sellers incur considerable costs in finding buying agents or intermediate goods demanders that are good matches for the variety they have to offer. As Swedish Trade Council export consultant Kent Goldmann (quoted in Nothdurft 1992, p. 32) stated of his clients that are marginal or failed exporters, "Sometimes their product isn't right for the market, or the country they chose was not a good fit, or their approach or agents are not right." Preferential group ties operating across markets are effective exactly because they overcome these information problems.

The adverse consequences of ignoring informational barriers become clear in the standard model's prediction that in any differentiated product sector a country exports a share of its output 
equal to the rest of the world's share of world spending. The usual remedy for this empirically false prediction is to assume "home preference" on the part of domestic consumers (see, e.g., Harrigan 1994). However, it does not make sense to suppose that domestic consumers prefer products made at home unless home products were produced with domestic consumers in mind. Yet in the standard model firms treat all of the world's consumers symmetrically when choosing which varieties to produce. There is no reason for Austrian firms, say, to tailor their products to the small Austrian market rather than the large German market.

In our opinion, the fact that this supposition nevertheless seems natural reflects the basic difference in information availability in the domestic market compared to the international market. In trying to formalize this intuition, we must first address the question of what a model of international trade in differentiated products with imperfect information should look like. We conceive of trade as a process of matching among distributors and producers, with consumers strictly in the background. A successful match is interpreted as a joint venture between two distributors, two producers, or one distributor and one producer. ${ }^{4}$ We then assume that an actor matching in the domestic market has complete information about others' types, and can approach whichever partner he chooses. When matching in the international market, on the other hand, a trader is unable to verify ex ante how suitable his partner is, and matching is random. ${ }^{5}$ The group

\footnotetext{
${ }^{4}$ We believe this to be a more accurate description of the nature of trade in differentiated products. On the basis of their interviews with mid-level and senior managers responsible for international sourcing and investment decisions, Egan and Mody (1992, p. 325) state that, "Most U.S. buyers [of manufactures] interviewed for this study preferred long-term, stable and direct relationships with both developed and developing country suppliers."

${ }^{5}$ In this respect we have maintained continuity with more traditional models of international trade: Jones (1995) argues that international trade is the study of economies where some markets are integrated and others are not. This assumption may nevertheless seem extreme, and especially inappropriate for large, regionally diverse countries. We feel, however, that it is a justifiable stylization given results such as those of McCallum (1995, p. 6 16), who found that, controlling for distance and GDP, "trade between two [Canadian] provinces is more than 20 times larger than trade between a province and a [U.S.] state."
} 
is able to extend to the international market the benefit of complete information that for non-members prevails only in domestic transactions.

Choosing this modelling strategy has two important advantages. First, it leads us naturally to investigate economy-wide implications. Thus our approach is different but complementary to the study of transmission of information within the group, a question whose focus is primarily microeconomic. ${ }^{6}$ Taking complete information within the group as our point of departure, we can go further in studying the general equilibrium effects stemming from the interaction of the group and the anonymous market. Since the existence and functioning of the ties we have described is very well documented empirically, we see our attention to aggregate and measurable economic variables as a step forward.

Second, by applying our analysis to groups whose membership is effectively inherited rather than actively pursued, we side-step the question of when and how the provision of information can be organized by market forces. This is an important issue: consultants that help firms to enter a foreign market are becoming increasingly common.' We hope to address this question in future research. For now, a simpler approach that takes the group as given is faithful to important empirical examples and in our view yields high returns.

In sections II-V below we develop and solve a simple, tractable matching model that embodies the difference in information availability between the domestic and international markets. We obtain the expected results that the volume of international trade is reduced by the

\footnotetext{
6otice that the canonical assumption in this literature is that the information transmitted concerns past actions (see, e.g., Kandori 1992).

${ }^{7}$ See Miller (1997) for a story of how a former Chase Manhattan executive parlayed his experience in the bank's Hong Kong-based mergers and acquisitions department into such a consultant group.
} 
informational barriers and that an information-sharing group is valuable for the economy as a whole--in fact its value can be computed in a straightforward fashion. More surprising are the distributional implications generated by the model. In particular, some group members choose not to use their ties, and their decision to enter the anonymous market instead always reduces per capita income of non-members, with the largest losses concentrated among those with the poorest domestic market alternatives. We derive these results and give intuition for them in sections VVI. In section VII we examine what happens if non-members can distinguish in advance of matching those traders who have access to the group, and we show how our model can be applied to the trade effects of migration. Suggestions for further research are presented in section VIII.

\section{The model}

The world is composed of two countries, each formed by a continuum of types, uniformly distributed along a line that extends from -1 to 1 . The distance between two types on the line is a measure of their diversity and an index of the gains from trade that matching of those two types would generate.

Output is indeed generated through bilateral matching. When an individual chooses to match domestically, he has complete information about all other domestic types, and can approach whomever he chooses. The total output from the match, to be divided between the two partners, is given by $\boldsymbol{z}_{\boldsymbol{i}}$, the Euclidean distance between them. With complete information, before matches are concluded traders compete for the most desirable partners, and in equilibrium this determines the share of output that in each match goes to each partner.

International matches can be more productive: total output is given by $\boldsymbol{h} \boldsymbol{z}_{i j}$, where $\boldsymbol{h}$ is a 
parameter larger than 1 capturing sources of gains from trade that are outside our model (comparative advantage, spreading out of fixed costs, or exchange of technical information). For simplicity, we assume $h \in(1,2]$. However, individuals are less adept at finding the correct distribution channel for their product in the foreign market, and face higher uncertainty than they do at home. To capture this lack of information, we assume that matching among international traders is random: when matching abroad, a trader cannot recognize ex ante the identity of his partner but has an equal probability of matching with any type.

In addition to larger uncertainty in the marketing of the product, traders entering a foreign market may also face uncertainty as to the strength of demand for the good they are offering. If the foreign country is similar to their domestic country, then they may safely assume that the market niche abroad will be similar to the one to which they have access at home. But if the two countries are substantially different, this second source of uncertainty adds itself to the difficulty of finding the right distribution channel. Pakistani machine-made rugs do not have a large market in Pakistan, where the middle class is small, the masses are too poor to buy them, and the upper class considers them in bad taste; but they sell extremely well in the United States, where the middle class is large and both less able and less inclined to distinguish machine-made from hand-made rugs. On the other hand, Egyptian candy-coated chickpeas are one of the most popular snack foods in Egypt, but have barely penetrated the U.S. market. Absent trade barriers, we could expect Pakistani machine-made rugs to fare poorly in Iran and Egyptian candy-coated chickpeas to sell well in the rest of the Arab world.

We can model trade between similar countries by assuming that while matching abroad is random, each trader maintains his location on the line. We call this the fixed location case. If the 
countries are dissimilar, on the other hand, we assume not only an equal probability of matching with any foreign trader, but also an equal probability of occupying any position on the line when engaging in foreign trade.' An agent learns his type abroad only after having entered the international market. We call this the random location case.

Traders can return at no cost to the domestic market if their international match is unsatisfactory. Thus an international partnership is accepted only if it yields a higher total return than the sum of what the two partners are sure to obtain in their domestic markets. With the lack of information preventing bidding for desirable partners, the net gains from trade are then assumed to be shared equally. In other words, we assume that the total return from international transactions is divided between the two partners according to the Nash bargaining solution where each trader uses his domestic return as threat point.'

We complete the model by introducing the role of group ties. Suppose that in each country a minority of types of mass $\boldsymbol{m}$ belongs to a specific group. This minority is distributed uniformly along the whole support of the line. To capture the information advantage provided by group ties, we assume that when a minority agent chooses to match internationally within the group, he has complete information about the location of all other types in the group, and can approach and bid for whomever he chooses." As before, the total output from this transaction is $h z$, but now, in the presence of complete information, the share that each partner receives is

\footnotetext{
'These assumptions can be seen as the extremes of a continuum in which traders' international market locations range from perfectly correlated to uncorrelated with their domestic market locations.

'Once matching has occurred, individuals' types are revealed: each agent "opens the other's books". In the case of random location abroad the partners' types in their own domestic markets are also learned upon matching.

${ }^{10}$ It has been stated of the overseas Chinese in Asia (Ziesemer 1996, p. 29), "Every key individual among them knows every other key figure."
} 
determined in equilibrium by competing offers for desirable partners. Alternatively, each member of the minority group can choose to forgo use of his ties and enter the anonymous international market where matching is random. The choice, however, must be made ex ante. In the fixed location case, a minority trader knows both his own type abroad and that of every minority member settled in the foreign country, but he must choose whether or not to use the ties before knowing the identity of his potential partner in the anonymous international market. In the random location case, the choice must be made before any type abroad is revealed. If trading through the group, all types within it will be revealed upon entering. In all cases, a trader always has the option of renouncing the international partnership, and returning home.

We assume that the minority is distributed uniformly because we want to concentrate on the informational advantage provided by the group, and thus we want no difference in the distribution of types. An implication of this assumption is that our results would be unaffected if group members offered free "access" to domestic markets to their foreign counterparts, provided that when indifferent a group member chooses to match with someone he knows rather than with someone who knows someone he knows.

Our model can be read as an assignment problem: different traders must match, and they are not all equally well-suited to one another. The equilibrium in the domestic market and among group members abroad is equivalent to the complete information solution in assignment models. The equilibrium in the anonymous international market then corresponds to the incomplete information solution without resampling. In this latter case, the canonical assumption in the literature is that all types face the same probability distribution of total match returns, because each individual is identical ex ante (see for example the discussion in Mortensen, 1988). 
In our model, this is equivalent to assuming that each individual trading abroad has the same probability of occupying any location on the line, or that countries' preferences are dissimilar--the random location case. The alternative assumption is that different types face different distributions of match returns. This more complex scenario that maintains ex ante heterogeneity is equivalent to the fixed location case, where preferences are similar across countries and each type preserves his location on the line when trading abroad. Some of our results will come from the contrast between these two modeling strategies.

\section{A preliminary remark}

Individual returns from matching domestically provide the reference point against which returns in the international market are evaluated. Thus we need to begin our analysis by characterizing the equilibrium of the complete information game, where traders bid competitively for desirable partners. The following proposition, established in a generic setting and proved in the Appendix, gives us the answer.

Proposition 1. Consider a continuum of types distributed on a line. Call \|z $z_{i}$ type $i$ 's distance from the median and $\mathrm{z}_{\mathrm{ij}}$ the Euclidean distance between types $i$ andj. If the matching of $i$ and $j$ results in total return $\mathbf{z}_{\mathbf{i j}}$, and each type is free to choose and bid for his matching partner, then in equilibrium type i's return $\mathrm{r}(\mathrm{i})$ will equal $\left\|\mathrm{z}_{i}\right\|$.

The proposition establishes that individual returns in equilibrium are determined uniquely for any distribution of types, as long as the support of the distribution is not discontinuous around the median (i.e., as long as there exists a unique median). Although the total return from a match depends on the distance between the two partners, competition for the most desirable types has the final effect of equalizing for each individual the payoff from all equilibrium matches: all 
extra-returns are competed away. Notice that the proposition cannot predict which matches will take place, but only that all matches must be between two types on opposite sides of the median (generating total returns equal to $\left.\left(\left\|z_{i}\right\|+\left\|z_{j}\right\|\right)\right)$. Because individual returns are determined uniquely, the indeterminacy of the matches is irrelevant.

The result is consistent with the properties of the general assignment problem. As is well known, with complete information competitive bidding for partners yields efficient pairing, and efficient pairing requires assortative matching (higher types with higher types) if each type's marginal contribution to total match output is increasing in the partner's type (and vice-versa in the opposite case)." In our case, each type's marginal contribution to total output is independent of the partner's type, as long as the two partners are on opposite sides of the median. Thus, not surprisingly, any match between two types on opposite sides of the median is efficient (and total output is invariant to the specific matches).

A general feature of the assignment problem is that efficient pairing pins down relative returns for different types within each group, but usually an external "anchor" is required to determine relative returns between the two groups (firms and workers, for example, or males and females). The external anchor is given by some measure of reservation utility. In our case, however, because matching is not between two predetermined groups, the median of the distribution provides the anchor. Because a priori any type can always match with the median, it is not possible for all types on one side of the median to earn extra returns over all types on the opposite side. Thus, as long as the support of the distribution of types is continuous around the

\footnotetext{
${ }^{11}$ See, for example, Becker (1973), Mortensen (1988), and Sattinger (1993). For a recent analysis, see Legros and Newman (1997).
} 
median, the multiple equilibria problem that usually plagues the determination of individual returns disappears. When the support is not continuous around the median, the indeterminacy surfaces again. A simple way of thinking about this case is noticing that any point in the "gap" of the support can be identified as a median; thus $\left\|z_{i}\right\|$ in the Proposition is not unique, but each equilibrium corresponds to a different median, and the measure of the "gap" in the support corresponds to the measure of the set of possible equilibria. However, for any point identified as the median, all equilibrium returns are determined uniquely, and we obtain a standard result in the literature on matching first proved by Gale and Shapley (1962): all individuals on a given side of the market agree on the welfare ranking of the different equilibria, and what is best for one side is worst for the other.

For our purposes, a strong but plausible requirement of symmetry is sufficient to rule out this source of indeterminacy. This is particularly important because Proposition 1 then guarantees that returns are determined uniquely for any distribution of types. Because expected returns in the domestic markets are the threat points used in bargaining in international transactions, expectations over these returns determine the distribution of types that choose to return home. Insuring the domestic returns are invariant to the distribution of returning types thus greatly simplifies the problem. We show in the Appendix that Proposition 1 allows us to establish the following:

Corollary 1. In any equilibrium in which the distribution of types in the markets is symmetrical around zero, if any domestic trade takes place type i's return in the domestic market must equal $\left|\mathrm{z}_{\mathrm{i}}\right|$, his distance from zero.

From now on, we concentrate on equilibria where the distribution of types in the markets is symmetrical around zero, and therefore we have $\left\|z_{i}\right\|=\left|z_{i}\right|$. Because in equilibrium $\left|z_{i}\right|$ represents 
type i's profitability in domestic trade, the arbitrary types space over which a distribution is assumed has immediate empirical counterpart in the different types' opportunities in the domestic market.

Finally, notice that as these preliminary results make clear, matching with complete information does not guarantee high returns. Your perfect match may be a very small market niche.

\section{Trade without group ties}

\section{A. Equilibrium}

To evaluate the impact of group ties, we must first derive the expected values of individual returns and of aggregate economic variables in their absence.

Define the expected volume of trade $E(T)$ as the expected mass of successful international matches for each country:

$$
E(T)=\int_{-1}^{1} p(i) d i
$$

where $p(i)$ is the probability that trader $i$ concludes a successful match abroad. The match is successful if its total return is higher than the sum of the returns that the two partners can obtain domestically. ${ }^{12}$

In the fixed location case, if $\boldsymbol{z}_{\boldsymbol{i}}$ is positive (the opposite case is just the mirror image), agent $i$ 's return from matching with agent $\mathrm{j}$ is $\left[h\left(\left|z_{i}-z_{j}\right|\right)-\left(z_{i}+\left|z_{j}\right|\right)\right] / 2+z_{i}$. A successful match between types $i$ and $\mathrm{j}$ requires:

\footnotetext{
${ }^{12}$ With a continuum of types, we can consider the probability of success for each trader as independent of other traders' matches.
} 


$$
\mathrm{h}\left(\left|z_{i}-z_{j}\right|\right) \geq z_{i}+\left|z_{j}\right|
$$

or, since $h$ is larger than 1 :

$$
\begin{array}{ll}
z_{j} \in\left[-1,[(h-1) /(h+1)] z_{i}\right] & \text { if } z_{i} \geq(h-l) /(h+1) \\
z_{j} \in\left[-1,[(h-1) /(h+1)] z_{i}\right] \cup\left[[(h+1) /(h-1)] z_{i}, 1\right] & \text { if } z_{i} \in[\mathrm{O},(\mathrm{h}-1) /(\mathrm{h}+1)]
\end{array}
$$

Recalling that the distribution of types is uniform, if we define $S(i)$ (illustrated in Figure 1) as the set of successful partners of $i$, then:

$$
p(i)=\operatorname{prob}(j \in S(i))= \begin{cases}\frac{1+[(h-1) /(h+1)] z_{i}}{2} & \text { if } z_{i} \geq(\mathrm{h}-1) /(\mathrm{h}+1) \\ 1-\frac{2 h}{h^{2}-1} z_{i} & \text { if } z_{i} \in[0,(h-1) /(h+1)] .\end{cases}
$$

The probability of concluding a successful match in the international market is not the same for everyone: it is exactly 1 at $\boldsymbol{z}_{\boldsymbol{i}}=0$, reaches a minimum at $\boldsymbol{z}_{\boldsymbol{i}}=(\mathrm{h}-\mathrm{l}) /(\mathrm{h}+1)$ and then rises again to $2 h /[2(h+1)]$ at $\boldsymbol{z}_{\boldsymbol{i}}=1$. It embodies two different factors: the desirability of any given type, according to his position on the line; and the bargaining power that each type has and that therefore reduces the net return for his partner. For example, $\boldsymbol{z}_{\boldsymbol{i}}=0$ is not a very desirable partner, but he is always an acceptable one because he lays no claims on the partnership's return prior to the equal partition of net gains. ${ }^{13}$

In the random location case, denote agent $i$ 's location in the international market by $\boldsymbol{y}_{\boldsymbol{i}}$, while his original location in the domestic market is denoted by $\boldsymbol{z}_{\boldsymbol{i}}$. His return from matching with agent $\mathrm{j}$ is $\left[h\left(\left|y_{i}-y_{j}\right|\right)-\left(\left|z_{i}\right|+\left|z_{j}\right|\right)\right] / 2+\left|z_{i}\right|$. Suppose $y_{i}>y_{j}$ (again, the opposite case is just the mirror image). This match is successful if

\footnotetext{
${ }^{13}$ Notice that although $z_{i}=0$ never returns to the domestic market, some individuals in his immediate neighborhood always do.
} 


$$
h\left(y_{i}-y_{j}\right) \geq\left|z_{i}\right|+\left|z_{j}\right|
$$

or:

$$
y_{j} \in\left[-1, \mathbf{Y i}-\left(\left|z_{i}\right|+\left|z_{j}\right|\right) / h\right] \text {. }
$$

An agent's location in the international market will now be either more or less favorable than his location in the domestic market. As we see from (2b), this implies that gains from trade are possible even when $h=1$, so that matching internationally is no more productive than matching domestically. As in the case of the Pakistani rug makers, it may simply occur that a trader's market niche abroad is more favorable than at home.

Exploiting symmetry, the probability of a successful match in the random location case is:

$$
p(i)=\operatorname{prob}(j \in S(i))=\int_{0}^{1} \operatorname{prob}\left[\left|y_{i}-y_{j}\right|>\left(\left|z_{j}\right|+z_{j}\right) / h\right] d z_{j}
$$

where $^{14}$

$$
\left.\operatorname{prob} /\left|y_{i}-y_{j}\right|>\left(\left|z_{j}\right|+z_{j}\right) / h\right]=(1 / 2) \int_{\left(z_{i} \mid+z_{j}\right) / h-1}^{1}\left[y_{i}-\left(\left|z_{j}\right|+z_{j}\right) / h+1\right] d y_{i} .
$$

Again exploiting uniformity, we have:

$$
p(i)=\operatorname{prob}(j \in S(i))=\left[1-6 h+12 h^{2}+(3-12 h)\left|z_{i}\right|+3 z_{i}^{2}\right] / 12 h^{2}
$$

As expected, $p(i)$ is now declining monotonically in $\left|z_{i}\right|$, the original location in the domestic market. With random location and random matching in the international market, net expected returns abroad must differ among traders only because their opportunities at home differ: the more profitable is domestic trade, the higher the probability that an individual may

\footnotetext{
${ }^{\mathbf{1 4}}$ Note that successful matches are only possible for $\mathrm{y}, \in\left[\left(\left|z_{f}\right|+z_{j}\right) / \boldsymbol{h}-1,1\right]$.
} 
reject the international match." (In the remainder of the paper, we will maintain the convention of numbering equations as a or $b$ depending on whether they refer to the fixed location or the random location case.)

Substituting (3a) or (3 b') in (1) and solving the integral, we obtain the expected volume of trade:

$$
\begin{aligned}
& E(T)=\frac{2 h}{1 \neq h} \\
& E(T)=2\left(1-\frac{1}{h}+\frac{7}{24 h^{2}}\right)
\end{aligned}
$$

Over the interval $h \in(1,2]$, for example, the expected share of international matches that are concluded successfully (i.e., $E(T) / 2$ ) increases monotonically from 0.5 to 0.667 , in the fixed location case, and from 0.292 to 0.573 in the case of random location.

If we define the expected value of trade $E(V T)$ in each country as the value accruing to its citizens as result of their international transactions, then:

$$
\begin{aligned}
& E(V T)=(1 / 2) \int_{-1}^{1} p(i)\left\{\left[h E\left(\left|z_{i}-z_{j}\right|\right)+\left|z_{i}\right|-E\left(\left|z_{j}\right|\right)\right] \mid j \in S(i)\right\} d i \\
& E(V T)=(1 / 2) \int_{-1}^{1} p(i)\left\{\left[h E\left(\left|y_{i}-y_{j}\right|\right)+\left|z_{i}\right|-E\left(\left|z_{j}\right|\right)\right] \mid j \in S(i)\right\} d i
\end{aligned}
$$

in the two alternative specifications. Using (2a') and (3a) (or (2b') and (3b')) and solving the integral, we obtain:

$$
\begin{aligned}
& E(V T)=\frac{2 h^{2}(2+h)}{3(1+h)^{2}} \\
& E(V T)=2\left(\frac{h}{3}-\frac{7}{24 h}+\frac{1}{8 h^{2}}\right) .
\end{aligned}
$$

\footnotetext{
${ }^{15}$ In both the fixed and random location cases, $p(i)$ is increasing in $h$, as expected.
} 
Finally, we can calculate expected GDP in each country as the total value of all transactions concluded by its citizens. This will differ from (6) because it will include the domestic exchanges concluded by traders whose international matches have proven less productive than their opportunities at home. For each individual $i$, total expected return equals:

$$
\begin{aligned}
& \operatorname{Er}(i)=(p(i) / 2)\left\{\left[h E\left(\left|z_{i}-z_{j}\right|\right)+\left|z_{i}\right|-E\left(\left|z_{j}\right|\right)\right] \mid j \in S(i)\right\}+(1-p(i))\left|z_{i}\right| \\
& \operatorname{Er}(i)=(p(i) / 2)\left\{\left[h E\left(\left|y_{i}-y_{j}\right|\right)+\left|z_{i}\right|-E\left(\left|z_{j}\right|\right)\right] \mid j \in S(i)\right\}+(1-p(i))\left|z_{i}\right| .
\end{aligned}
$$

Because the probability of matching with any partner is the same for all types, expected returns must be increasing in $\left|z_{i}\right|$, the domestic fall-back option.

We define expected GDP $(E(G D P))$ as:

$$
E(G D P)=\int_{-1}^{1} \operatorname{Er}(i) d i
$$

With the appropriate substitutions:

$$
\begin{aligned}
& E(G D P)=\frac{2\left(h^{3}-1\right)}{3\left(h^{2}-1\right)} \\
& E(G D P)=\frac{2 h}{3}+\frac{7}{12 h}-\frac{1}{8 h^{2}} .
\end{aligned}
$$

The ratio of expected trade to expected GDP is given by $E(V T) / E(G D P)$. Over the interval $h \in(1,2]$, this ratio increases from 0.5 to 0.762 , in the fixed location case, and from 0.296 to 0.693 in the case of random location. In our model, both the expected volume of international transactions and the ratio of the value of trade to GDP are higher in the case of countries with similar preferences, i.e., in the fixed location case, because the probability of a successful match abroad is higher (with the exception of types in the immediate neighborhood of $\left|z_{i}\right|=$ $(h-1) /(h+1))$. 


\section{B. Discussion}

We wish to highlight several features of the equilibrium of our model without group ties that do not characterize equilibria in the standard model of trade in differentiated products (e.g., Helpman and Krugman 1985).

Informational barriers to trade. Consider the fixed location case. If agents were able to match with complete information in the foreign as well as the home market, in the symmetrical equilibrium the return to each agent will equal $h\left|z_{i}\right|$ (see Corollary 2 below). Since international matching is more productive than domestic matching $(h>1)$, all international matches would be successful, and the ratio of expected trade to expected GDP would always be one. It follows that in the fixed location case with $h>1$ we can attribute the result that $E(V T)$ is strictly less than $E(G D P)$ to the effects of random matching alone: the value of trade in our model is reduced by informational barriers.

Home preference. In the random location case an agent who matches with complete information in the international market may nevertheless do less well than matching domestically. Specifically, these international matches fail if $h\left|y_{i}\right|<\left|z_{i}\right|$. We can interpret the domestic matching that results as a pure "home preference" effect since it occurs only because one is matching (trading) with a dissimilar country. We can thus think of $E(G D P)-E(V T)>0$ in the random location case as resulting from a combination of random matching and home preference effects.

Anent heterogeneity. We have seen that agents differ in the probabilities with which they match successfully abroad. In the fixed location case, although the probability of a success\&l international match is non-monotonic in the profitability $\left|z_{i}\right|$ of an agent's domestic market niche, 
it is nevertheless the case that agents with the most favorable domestic market niches contribute disproportionately both to the volume of trade $E(T)$ and to its value $E(V T){ }^{16}$ This result exemplifies Linder's (1961, p. 88) statement, "International trade is really nothing but an extension across national frontiers of a country's own web of economic activity." In contrast, in the random location case the probability of a successful international match declines monotonically with $\left|z_{i}\right|$, so that agents with the least favorable domestic market niches participate disproportionately in the volume of international trade $E(T)$. Linder's insight no longer holds. The greater participation of the low $\left|z_{i}\right|$ agents, however, does not carry over entirely to their share of the value of trade because of their weak bargaining power: the lower half of agents only accounts for about half of $E(V T) .^{17}$

The ratio of trade to GDP with countries of unequal size. In the standard model of trade in differentiated products, the ratio of trade to GDP for a country approaches one as its trading partner grows large. This is unfortunate because it prevents the use of the "small country" assumption that has proved so useful in traditional trade theory, and because it is empirically inaccurate." Since our work is partially motivated by overpredictions of the volume of trade by

\footnotetext{
${ }^{16}$ In the fixed location case, the share of $E(V T)$ accounted for by agents located between $|1 / 2|$ and |1| goes from 75 to 68 per cent as $h$ increases from 1 to 2 .

${ }^{17}$ In the random location case the share of $E(V T)$ accounted for by agents located between 0 and $|1 / 2|$ declines monotonically from 57 to 48 percent as $h$ increases from 1 to 2 . An alternative way to think about agents' heterogeneity is to ask what would happen in the presence of a fixed cost to enter the international market. In the fixed location case, as the cost of going abroad increases the first types to choose to trade exclusively in the domestic market are those in the neighborhood of $(\mathrm{h}-1) /(\mathrm{h}+1)$; the types who still expect to gain from going abroad are those concentrated around zero and those at the high end of the distribution. In the case of random location, types near $|1|$ are the first to drop out of the international market.
}

${ }^{18}$ The ratio of trade to GDP approaches one because the number of varieties of diierentiated product made by the trading partner grows large relative to the number produced domestically, causing the ratio of imports to domestic consumption to approach one given the symmetric treatment of home and foreign consumers mentioned in the Introduction. Documenting this inaccuracy is not as straightforward as one would wish. Typically one cannot observe 
the standard model, it is useful to see how our model behaves in the "small country" setting.

Let us suppose that for every domestic agent there are $\mathrm{N}$ corresponding foreign agents (we have fixed Nat one until now). Since all agents attempt to match in the international market and rationing will be random with respect to location on the line, any foreign agent matches with a domestic agent with probability 1/N. Denoting the large foreign country with an asterisk, it follows that $\operatorname{Er}(j)=(1 / N) \operatorname{Er}(j)+[(N-1) / N]\left|z_{j}\right|$, where $\operatorname{Er}(j)$ is given by equation (7a) or $(7 \mathrm{~b})$ for the fixed or random location cases, respectively. Integrating yields $E\left(G D P^{*}\right)=E(G D P)+$ $\mathrm{N}-1$, where $E(G D P)$ is given by equation (9a) or (9b). Note that $E\left(G D P^{*}\right.$ ) reduces to $E(G D P)$ for $\mathrm{N}=1$. Since $E\left(V T^{*}\right)=E(V T)$, where $E(V T)$ is given by equation (6a) or $(6 \mathrm{~b})$, the ratio of trade to GDP for the large country $E\left(V T^{*}\right) / E\left(G D P^{*}\right)=E(V T) /[E(G D P)+\mathrm{N}-1]$, which declines monotonically with country size and approaches zero as $\mathrm{N}$ grows large. Thus as the foreign country comes to approximate the "rest of the world" it becomes a closed economy. In contrast, the openness of the smaller (home) country does not change.

\section{Trade with group ties}

What are traders' returns in equilibrium, when matching within the group? There are two reasons why Proposition 1 does not apply automatically to the new problem. First, contrary to

\footnotetext{
consumption of tradeables directly but must instead compute "apparent consumption", defined as production plus imports minus exports. This computation in turn runs into difficulties because trade data are categorized differently than production data. The Compatible Trade and Production Database (see Berthet-Bondet et al., 1988, for a description) converts 1970- 1985 trade data for 22 OECD countries to an International Standard Industrial Classification basis for manufacturing industries. In 1985, 14 of these countries had manufacturing production equal to less than two percent of the OECD total. 10 of these countries were parties to major multilateral trading agreements that should have made them quite open to international trade. Their ratios of manufacturing imports to apparent consumption were: Austria 0.36, Belgium-Luxembourg 0.99, Denmark 0.52, Finland 0.28, Greece 0.30, Ireland 0.7 1, Netherlands 0.75, Norway 0.46, Portugal 0.32, and Sweden 0.41. Only Belgium-Luxembourg appears close to conformance with the predictions of the standard model, but it also shows ratios in excess of 100 percent for 10 of the 283 digit industries for which these ratios are reported, casting some doubt on the reliability of the results for this country.
} 
the case of domestic transactions, traders matching within the group now have an outside option (they can return home if unsatisfied with the deal they are able to conclude abroad). Second, international trade must take place between citizens of the two countries. Thus the set of agents is divided into two subsets whose members are restricted to trading with each other. As we discussed in Section 3, this is the origin of a standard indeterminacy in the solution to the assignment problem.

Nevertheless, we show in the Appendix that restricting our focus to symmetrical equilibria is sufficient to yield an intuitive generalization of Corollary 1. We can establish:

Corollary 2. An equilibrium is symmetrical if the distribution of types in the markets is symmetrical around zero, and identical types in the two countries make the same decision with respect to participation in the group. In the symmetrical equilibrium, if any trade takes place in the group, the equilibrium return in the group for a trader at location $\mathrm{y}_{\mathrm{i}}$ must equal $\mathrm{h}\left|\mathrm{y}_{\mathrm{i}}\right|$.

We can now investigate which members of the minority group will exploit their ties. Imagine an equilibrium where all members choose to use the ties. This reduces the density of potential partners in any given interval for any trader entering the anonymous international market. However, because the distribution of minority agents is uniform, the probability of a partner belonging to the "successful" interval is unchanged, and because the mass of traders entering the market is reduced by an equal proportion in both countries, the matching is unchanged. Thus, if all members use the group, expected returns for non-members continue to be defined by (7) and the probabilities of success by (3). By Corollary 2, returns to members are given by $\boldsymbol{h}\left|z_{j}\right|$ in the fixed location case, and $h\left|y_{i}\right|$ in the random location case. In this latter case, the group trade may fail because returns at home may be higher,

These observations alone are enough to suggest where the problem may lie. In the fixed 
location case, consider $z_{i}=0$. The complete information existing within the group reveals his low productivity and insures a zero return; in the anonymous market, on the other hand, his lack of bargaining power makes him an acceptable partner, and he benefits from the higher gains associated with international trade. ${ }^{19} \mathrm{He}$ will always prefer the market. In the random location case, consider $\boldsymbol{z}_{\boldsymbol{i}}=1$. With probability 1 , he will have a worse location abroad than he does at home. If $h$ is low, his return in the group is unlikely to dominate his domestic return; in the anonymous market, however, he benefits from his high bargaining power and the chances to do better than at home may well be higher, Thus he may prefer the market. In other words we expect that there will be self-selection in the use of the group ties, and that the types preferring the market will be different in the two cases of fixed and random location, their identities determined by the interplay between the gains from trade, as summarized by $h$, and their bargaining power. The following proposition makes this intuition precise:

Proposition 2. In both the fixed and random location cases the symmetrical equilibrium with group ties is unique:

(i) In the fixed location case, there exists a positive number $\alpha(\mathrm{h}, \mathrm{m})$ such that all members in $[0,|\alpha(\mathrm{h}, \mathrm{m})|]$ prefer the market, and all members in $(|\alpha(\mathrm{h}, \mathrm{m})|, 1]$ prefer the ties.

(ii) In the randm location case, there exists a value $\overline{\mathrm{h}}>1$ such that for all $\mathrm{h} \geq \overline{\mathrm{h}}$ all members participate in the group, while for all $\mathrm{h}<\overline{\mathrm{h}}$ there exists a positive number $\beta(\mathrm{h}, \mathrm{m})$ such that all members in $[0,|\beta(\mathrm{h}, \mathrm{m})|]$ prefer the ties, and all members in $(|\beta(\mathrm{h}, \mathrm{m})|, 1]$ prefer the market.

The proposition is proved in the Appendix. When countries are similar, the complete information existing within the group leads producers with relatively unprofitable market niches to attempt the anonymous market. But when the foreign market is different from the domestic one,

\footnotetext{
${ }^{19}$ Equation (7a) implies $\operatorname{Er}(0)=(\mathrm{h}-1) / 4$.
} 
if international trade is sufficiently productive the information provided by the ties is of sufficient value to all agents that all of them choose to exploit it. Otherwise it is the types with higher expected returns at home who prefer the market, because the market and not the group will acknowledge and reward their privileged standing at home. Notice that this occurs although both the market and the group allow a trader to return to his domestic option if he so desires.

The formal derivation of the interval of minority traders foregoing the group is somewhat involved because, in the market, the density of potential partners is no longer uniform over the entire support, but is higher in the intervals that include minority traders. If we let $\mathrm{C} \equiv(2-$ the total length of these intervals), i.e., $\mathrm{C}=2(1-a)$ in the fixed location case, and $2 \beta$ if location is random, it is not difficult to verify that:

$$
\operatorname{prob}\left(z_{j} \in[s, v]\right)= \begin{cases}\frac{v-s}{2-(m / 2) C} & \text { in the high density intervals } \\ \frac{(v-s)(2-m)}{[2-(m / 2) C] 2} & \text { in the low density intervals. }\end{cases}
$$

It follows from Corollary 2 that in the symmetrical equilibrium returns in the group are determined uniquely. Thus the two variables $a$ and $\boldsymbol{\beta}$ must satisfy:

$$
\begin{aligned}
& E r^{M}(\alpha)=h|\alpha| \\
& E r^{M}(\beta)=h / 2+\beta^{2} /(2 h),
\end{aligned}
$$

where the superscript $M$ indicates that expected market returns must be calculated taking into account the existence and composition of the subset of minority traders that avoids the market. The right-hand side of (11) is the expected return from using the ties. In (1 lb), this equals $h$ times the expected location if successful plus the fall-back domestic return if unsuccessful. Expected returns in the anonymous market can be obtained from equations (7a) and (7b), but with 
probabilities and expected values now reflecting the different densities, as described in $(10){ }^{20}$ The comparative statics properties of a and $\boldsymbol{\beta}$ are summarized by the following Proposition:

Proposition 3. An increase in the profitability of trade leads to a decline in the share of members who rely on the ties in the fixed location case, but to an increase in case of random location (and $\mathrm{h}<\overline{\mathrm{h}}$ ). An increase in the percentage of the population belonging to the minority group always leads to an increase in the percentage of members relying on the ties (unless all of them already do so). I.e. :

$$
\begin{aligned}
& \mathrm{d} \alpha / \mathrm{dh}>0, \quad \mathrm{~d} \alpha / \mathrm{dm}<0 \quad \forall \mathrm{h} \in(1,2], \\
& \mathrm{d} \beta / \mathrm{dh}\left\{\begin{array}{ll}
>0 \\
=0
\end{array} \quad \mathrm{~d} \beta / \mathrm{dm} \begin{cases}>0 & \mathrm{~h} \in(1, \overline{\mathrm{h}}) \\
=0 & \mathrm{~h} \in[\overline{\mathrm{h}}, 2] .\end{cases} \right.
\end{aligned}
$$

The proof is in the Appendix.

In the fixed location case, an increase in $h$ increases market returns through two channels. For any given partnership, it increases the return from the match; but in addition, a higher $h$ also increases the ex ante probability of a successful partnership, and particularly so for those types close enough to zero to have potentially successful partners on their two sides. The effect of higher $h$ on returns within the group, on the other hand, is linear in $\boldsymbol{z}_{\boldsymbol{i}}$. Thus we expect the relative attractiveness of the market to increase for low types, and decrease for high ones. Proposition 3 states that a, the marginal type indifferent between market and group, is always low enough to fall in the first set. In the representative case $m=0.4$ (i.e., when the minority is 20 per cent of the population), the share of minority traders who forgo the ties goes from 16 to 19 per cent as $h$ moves from 1 to 2 .

In the random location case, on the contrary, an increase in $h$ decreases the relative profitability of the market, and thus the share of minority traders who forgo their ties. The

\footnotetext{
${ }^{20}$ The procedure is straightforward but a bit cumbersome, and we report the details and the explicit equations in the Appendix.
} 
difference stems from the fact that in the fixed location case all matches within the group are accepted for $h>1\left(\operatorname{prob}\left(h\left|z_{i}\right|>\left|z_{i}\right|\right)=1\right)$ while in the random location case the probability of acceptance $\left(\operatorname{prob}\left(h\left|y_{i}\right|>\left|z_{i}\right|\right)\right)$ is strictly increasing in $h$. As $h$ increases from 1 to $\bar{h}(\approx 1.36)$ with $m=0.4$, the share of minority members entering the market declines from 20 percent to zero.

Changes in $m$, the proportion of the population that belongs to the minority, may also affect the choice of market versus group. If all members match in the group, $m$ has no impact on expected returns because, as we have argued above, the probabilities of different matches in the market are unaffected. When some minority traders from a specific segment of the economy enter the market, however, a higher $m$ increases the relative probability of matches with types drawn from that segment. As shown in Proposition 4 below, in equilibrium this decreases expected market returns for individuals located within or in the proximity of that segment in both the fixed and random location cases. Because $m$ does not affect returns within the group, it follows that, ceteris paribus, a higher $m$ decreases the attractiveness of the market for the marginal member and increases the share of members relying on the ties. In all our numerical examples, however, we found the magnitude of the effect to be small. For example, in the fixed location case with $h=2$, if the share of the population belonging to the minority group goes from 10 to 50 per cent, the share of members relying on the ties increases from 80.5 per cent to 82 per cent; in the random location case with $h=1$, the same change in $m$ increases the share of members relying on the ties from 79 to 81 per cent.

\section{The welfare effects of group ties}

In many countries substantial income differentials exist between ethnic minorities 
acknowledged to have access to international trading "societies" and the majority populations.*'

It is also true that most governments run trade promotion organizations with the professed intent to achieve the results we ascribe here to the group. ${ }^{22}$ In this section we investigate the welfare effects of the preferential ties on the economy as a whole, and on those traders who have, or have not, access to them.

If all members prefer to match within the group, we can easily see that in our model the existence of group ties is Pareto improving. Expected returns for traders in the anonymous market are unchanged; each minority trader has the option of earning the same return he would earn in the absence of the ties, but finds the group superior. Thus the equilibrium with group ties is Pareto superior: all members do strictly better and all non-members are unaffected. This is in fact what happens in the case of random location and sufficiently high $h$.

However, when some members prefer the market, the answer is less straightforward because the entry of some, but not all, minority traders in the market distorts expected returns. The change in the relative frequency of different types in the market tends to hurt at least some of the other market participants, either because their type has now become relatively more abundant (in the fixed location case), or because of the disproportionate presence of types with strong bargaining positions but no greater productivity on average (in the random location case). The

\footnotetext{
${ }^{\mathbf{2 1}}$ Good examples are ethnic Chinese in Southeast Asia and ethnic Indians in East Africa. Of course these income differentials cannot be attributed entirely to superior international trade opportunities for the minorities, but it appears that these contribute significantly,

"The Hong Kong Trade Development Council is widely regarded as one of the most successful examples. According to Keesing (1988, p. 20), "HKTDC sees its central task as 'matchmaking' between foreign buyers and Hong Kong firms wishing to export." Since this policy allows all foreign agents potential access to the "group," while in practice not all domestic firms are represented due to limited administrative capacity, the HKTDC and similar trade promotion organizations are actually more closely analogous to the immigrant societies studied in section VII.B below.
} 
following Proposition, proved in the Appendix, provides the general answer:

Proposition 4. I. The existence of ties among a minority group always increases expected GDP in the economy.

2. When all members use the ties, expected returns for non-members are not affected; expected returns for all members rise.

3. When some members choose to enter the market:

i) Expected per capita GDP always rises for members, but falls for non-members.

ii) Within each set, different types fare differently:

(a) All members who join the market are worse-off than in the absence of the ties. All members who use the ties except those near a ( $\beta$ ) are better-off: For all members, the percentage change in expected returns is monotonically increasing in $\left|z_{i}\right|$ in the fixed location case. In the random location case the percentage change in expected returns is monotonically decreasing in $\left|\mathrm{z}_{\mathrm{i}}\right|$ for all members who use the ties and monotonically increasing in $\left|\mathbf{z}_{\mathrm{i}}\right|$ for all members who join the market.

(b) In the random location case, all non-members are worse-off than in the absence of the ties. In the fixed location case, there exists an $\hat{\mathbf{h}}(\mathbf{m})$ such that for all $\mathrm{h}<\hat{\mathbf{h}}(\mathbf{m})$ all non-members are worse off than in the absence of the ties; for $\mathrm{h} \geq \hat{\mathbf{h}}(\mathbf{m})$ all $\left|\mathbf{z}_{i}\right| ' s<\left|\hat{\mathbf{z}}_{\mathbf{i}}(\mathbf{h})\right|$ are worse-off and all $\left|\mathrm{z}_{\mathrm{i}}\right|$ 's $>\left|\hat{\mathbf{z}}_{\mathrm{i}}(\mathrm{h})\right|$ are better off than in the absence of the ties, where $\left|\hat{z}_{\mathrm{i}}(\mathrm{h})\right| \in(\mathrm{a}, 1]$. In all cases, low types are hurt most: the percentage loss in expected return is monotonically declining in $\left|\mathbf{z}_{\mathbf{i}}\right|$.

Proposition 4 states that the existence of the group is always beneficial to the economy as a whole, but causes systematic distributional effects. Figure 2 summarizes these findings. There are types who gain and types who may lose, with the gains concentrated in the group, whose members have access to the ties, and the losses concentrated among non-members, shunned from the preferential information channels. For example, if the mass of members is 20 percent of the population, as $h$ increases from 1 to 2 the existence of the group increases expected GDP for the economy as a whole from 0 to 6 percent above the no-ties reference values in the fixed location case, and from 3 to 7 percent in the random location case. However, among members alone, 
expected per capita income rises from 0 to 31 percent over the no-ties values in the fixed location case, and from 19 to 36 percent in the case of random location. Among non-members, the maximum percentage loss in expected per capita income reaches half a percent in the fixed location case when $h=2$, and 0.4 percent when $\boldsymbol{h}$ equals $\mathbf{1}$ in the random location case.

The change in expected per capita income is the result of the change in trade flows caused by the ties. Proposition 4 can be reinterpreted as stating that the existence of a group sharing preferential information abroad increases the ratio of trade over GDP for the group in particular, and for the economy as a whole, but decreases it for those traders who are not members whenever members self-select in using their ties. Notice that this conclusion holds whether trade is between similar or between different countries (i.e., in both the fixed and the random location cases). The injury to market traders is the result of the reliance on the group of the more desirable trading partners.

Not only are distributional effects present between the two sets of agents, but different types within each set also fare differently. Among non-members, whenever there is a loss, the loss is greater the smaller is an agent's domestic market niche, since low $\left|\boldsymbol{z}_{\boldsymbol{i}}\right|$ types both rely more heavily on the international market and have lower bargaining power. For example, in the fixed location case with $m=0.4$ and $h=2$, the expected loss to $z_{i}=0$ (compared to the no-ties equilibrium) is of the order of 3.7 percent, while $\left|\boldsymbol{z}_{\boldsymbol{i}}\right|=1$ experiences a very slight expected gain ( 0.1 per cent). In the case of random location, if $h=1$, the expected loss to $z_{i}=0$ is roughly 3 percent but only 0.05 percent for $\left|z_{i}\right|=1$.

Among members, on the other hand, gains from the existence of the group ties result from the combination of two opposing effects: the ability to match with complete information abroad 
is tempered by the loss of the bargaining power that can be exploited in the imperfect market. In the fixed location case, the first effect always dominates: the group ties favor high types. With $m$ $=0.4$ and $h=2$, the expected return to a minority trader of type $\left|z_{i}\right|=1$ rises by more than 40 percent; the marginal member, just indifferent between market and ties, suffers a loss of 1.4 percent. In the random location case, the ex ante value of the appropriate niche abroad is the same for all types, while the renounced bargaining power is greater the larger is $\left|z_{i}\right|$. Thus the group ties favor low $\left|z_{i}\right|$ types. For example, with $m=0.4$ and $h=1$, the expected return to a minority trader of type $\boldsymbol{z}_{\boldsymbol{i}}=0$ rises by 220 percent while the trader of type $|\boldsymbol{\beta}|(\approx 0.8)$ suffers a loss of just over 0.1 percent.

In summary, our analysis supports the view that coethnic societies, business groups operating across international borders, or institutions devoted to the creation of better information channels in foreign markets, are valuable. It stresses, however, that under most circumstances those excluded from these channels, or somehow less able to exploit them, will be hurt. Since those most hurt are the agents with the poorest domestic market niches, measures to redress this grievance can be easily rationalized as instruments for redistribution. It is thus not surprising to find de jure or de facto requirements imposing partnerships with ethnic nationals in countries where coethnic societies are important. ${ }^{23}$

\section{Extensions}

In sections 5 and 6 we have studied the consequences of the presence of a minority of

\footnotetext{
${ }^{23}$ In the case of the Overseas Chinese, we find de jure requirements in Malaysia (Jesudason 1989) and de facto requirements in Indonesia (Robison 1986), for example.
} 
traders within which every agent knows the type of every other agent. This description of the group was a stylization of abundant evidence, some of which was cited in the Introduction. In the next two subsections, we make assumptions that extend beyond the existence of complete information within the group to non-random interactions between members and non-members. In contrast to intra-group relations, systematic evidence on this subject is scarce, and our modeling choices should be seen as suggestive but tentative.

\section{A. Discrimination}

We have shown in the previous section that the existence of group ties lowers per capita expected returns for non-members whenever it modifies the composition of the market. But suppose that agents can distinguish group members from non-members in advance of matching, so that the international market is no longer completely anonymous. Would not non-members simply refrain from partnerships with minority traders? Whether this requirement is met in reality has not been adequately studied. While coethnicity or business group membership may be transparent to home country nationals, it may often not be for foreigners. A Thai national may recognize that another Thai businessman is of ethnic Chinese origin, but an Indonesian national (not of ethnic Chinese origin) may not be able to. Encaoua and Jacquemin (1982, p. 26) note that business groups in France "have no legal existence and are not identified in official censuses. Each subsidiary maintains its legal autonomy and keeps separate accounts."

A natural question is whether an equilibrium could emerge where there is "complete segregation": only non-members match in the market. We can prove that this outcome is 
possible, in both the fixed and the random location cases. ${ }^{24}$ With complete segregation, non-members fare as in the no-ties equilibrium and the distributional implications can be easily deduced from the previous section. On average, non-members are always better off, but the gains fall mostly on the least profitable types located around zero. ${ }^{25}$ As for members, per capita income for the group must fall, with all losses concentrated on those types that would prefer to match in the market but are now prevented from doing so. The aggregate welfare results are less obvious: although we have refined the information set of all agents, our model its too distant from a firstbest solution to allow the deduction that economy-wide GDP must rise. In fact, we find that it rises in the random location case, but falls in the case of fixed location.

It would be misleading to conclude, however, that whenever group members can be distinguished from non-members in advance of matching, segregation will result. In the fixed location case we can demonstrate that other equilibria are possible. Given our discussion of Proposition 4, the following equilibrium with "mixed" market partnerships seems especially plausible. A mass of members close to zero enters the market, gambling that they will be matched with high $\left|z_{i}\right|$ 's. At low $h$, most will fail and return home (the mass of members in the market is much larger than the mass of non-members willing to match with them), but some will succeed, justifying the initial gamble. As $h$ increases, the probability of being rationed decreases rapidly.

\footnotetext{
${ }^{24}$ To support the segregated equilibrium all members must believe that they would be shunned, if they tried to match in the market, and all non-members must believe that any member present in the market would be a worse partner than the average non-member. It is not difficult to find beliefs for non-members that do indeed support segregation as a sequential equilibrium. For example, in the fixed location case, the belief that only members located at $-1 / 2+\boldsymbol{e}$ and $1 / 2-\boldsymbol{e}$ would enter the market (e $>0$ but close to zero) supports segregation, since all non-members would then prefer to match only among themselves, in the random location case, the belief that only members characterized by $\left|z_{i}\right| \geq \beta$, as in the previous section, would enter the market yields the same implication.

${ }^{25}$ In the fixed location case, if $\boldsymbol{h}$ is sufficiently high, the more profitable non-members located near $[\mathbf{1} \mid$ are actually harmed.
} 
Thus in this equilibrium some mixed partnerships will be observed, and the more so the higher is h.

An interesting feature of this equilibrium is the reversal of the welfare effect of discrimination on the two sets of agents as $h$ increases. At low $\boldsymbol{h}$, members on average are hurt, with the decline in expected returns concentrated on the low types that are constrained in their desire to enter the market. At the same time, expected per capita GDP for non-members rises, with the gains concentrated on low types who can now refrain from any match with members. At high $h$, however, as minority members near zero match with high $\left|z_{i}\right|$ non-members, the latter effectively exit the non-member market. The final result is that discrimination hurts the non-members who actively discriminate, while being beneficial to those who do not, and to the minority. For all $h$, we find that aggregate welfare rises.

\section{B. The trade effects of migration}

Often immigrants come to constitute a coethnic society in their host country, facilitating international trade between that country and their country of origin. Indeed, as mentioned in the Introduction, this is one of the most important and well-documented instances of the use of coethnic ties in international trade.

Consider an ethnically homogeneous country and suppose that a uniformly distributed subset of its population has migrated to a second country. For simplicity let us also suppose that the two countries are of equal size (post-migration): thus the country of origin is of size 2 and consists of a single ethnic group; the host country has an ethnic minority of size $m$ and a mass of natives of size $(2-m)$. 
Assume now that when traders from the country of origin are rationed in their attempt to match within the coethnic group, they can match randomly in the anonymous international market. We can then make two preliminary observations. First, there is an equilibrium where all traders from the country of origin have the same probability of being rationed when trying to use the ties. It follows, and this is the second observation, that if in the absence of rationing expected returns within the coethnic group are higher than in the market, it is still an equilibrium to (attempt to) use the ties.

It is not difficult to see that in this example the analysis is exactly identical to what we presented before. Consider any interval of the support such that coethnics from that interval prefer to use the ties. In the country of origin it is still the case that a fraction $m / 2$ of traders in that interval will be able to exploit the coethnic group, and that this fraction will be distributed uniformly; the remaining fraction $(2-m) / 2$, again distributed uniformly, will enter the market. Given the assumption we have maintained all through the paper that coethnics meeting in the market are unable to rely on the coethnic ties (i.e., do not have complete information) everything follows as in the preceding sections. ${ }^{26}$

We can reinterpret the effect of the ties in increasing trade as the trade effect of migration. For example, using the equations of sections 4 and 5, if $h$ equals 1.5 , migration of 1 per cent of the population raises the value of trade by 0.85 percent in the fixed location case, and by 0.8 percent in the case of random location.

\footnotetext{
${ }^{26}$ Notice that this remains true for any example where the masses of coethnics $\boldsymbol{m}^{\mathbf{1}}$ and $\boldsymbol{m}^{\mathbf{2}}$ in country 1 and country 2 , respectively, are different and $\boldsymbol{m}^{\mathbf{1}} \boldsymbol{>}_{\boldsymbol{m}}$. However, although aggregate values are unchanged, we should note that the expected per capita income of coethnics in country 1 is lower than that of coethnics in country 2: the larger is the mass of country 1 coethnics relative to country 2 coethnics, the less they benefit from the coethnic society.
} 
Although our model can easily handle this example, the example itself is probably not the best way to represent migration. For one thing, we would want to treat the decision to migrate as endogenous. The incentive to migrate is the ability, once in the host country, to exploit one's coethnic ties to the country of origin. From our results above it is clear that this incentive will vary across types. Thus, we should not assume that the migrants who constitute the coethnic society are uniformly distributed on the line. Second, in our example most coethnics in the country of origin are rationed in their attempts to match abroad within the coethnic group. This lends increased importance to a question that can be set aside when the minority masses are equal (see page 9 above): to what extent are domestic group members able and willing to introduce foreign members to their non-member compatriots, about whom they (by assumption) have full information? Little is known about this, in any systematic manner, and it seems prudent to await more information before proceeding further.

\section{Suggestions for future research}

In order to focus on what is new in our approach we have omitted any role for prices. Yet some of the most interesting results of our approach should come from the interaction of the matching process we have described with market prices. For example, suppose that production and marketing required not only the matching of two (appropriate) types, but also the use of a non-produced input (labor), in different abundance in the two countries. To what extent will the existence of the ties affect the pressure towards factor-price equalization? Or suppose that group members, while benefiting from superior information, had higher costs than non-members. Under what conditions would they still choose to match within the group? 
We have already mentioned the possible application of our model to government trade promotion organizations, so widely observed yet so little studied. A more speculative application, which would require considerable modification of the model, is to the alleged benefit from government coordination of complementary domestic investments in less developed countries given the difficulty of finding the inputs that match domestic needs in the international market (Murphy, Shleifer, and Vishny 1989; Rodrik 1995).

While our motivation has been trade in differentiated products, we hope to have contributed to a wider literature on the effects of a group that shares superior information within a larger anonymous market. In this respect our paper reaches similar results to Montgomery (1991). Studying firms' hiring through personal referrals, Montgomery finds that the existence of referrals depresses market wages because it distorts the composition of the anonymous market towards lower ability workers. As in our case, the existence of an alternative channel for allocations, chosen selectively by the more desirable individuals, has negative effects for those agents who are limited to the market. Investigating the extent to which these findings generalize is another promising avenue for future research. 


\section{References}

Becker, Gary. 1973. “A Theory of Marriage: Part 1.” Journal of Political Economy 81 : 813-46.

Berthet-Bondet, Claude, Derek Blades, and Annie Pin. 1988. The OECD Compatible Trade and Production Data Base 1970-1985. OECD Department of Economics and Statistics Working Paper No. 60 (November).

Chin, Ku-Sup, In-Jin Yoon, and David A. Smith. 1996. "Immigrant Small Business and International Economic Linkage: A Case of the Korean Wig Business in Los Angeles, 1968-1977." International Migration Review 30 (Summer): 485-5 10.

Dobson, Wendy, and Chia Siow Yue, eds. 1997. Multinationals and East Asian Integration (Singapore: IDRC Books and ISEAS).

Egan, Mary Lou, and Ashoka Mody. 1992. "Buyer-Seller Links in Export Development." World Development 20 (March): 321-334.

Encaoua, David, and Alexis Jacquemin. 1982. "Organizational Efficiency and Monopoly Power: The Case of French Industrial Groups." European Economic Review 19: 25-5 1.

Gale, David, and Lloyd Shapley. 1962. "College Admissions and the Stability of Marriage." American Mathematical Monthly 69: 9-15.

Gould, David M. 1994. "Immigrant Links to the Home Country: Empirical Implications for U.S. Bilateral Trade Flows." Review of Economics and Statistics 76 (May): 302-3 16.

Granovetter, Mark. 1994. "Business Groups." In Neil J. Smelser and Richard Swedberg, eds., The Handbook of Economic Sociology (Princeton, NJ: Princeton).

Harrigan, James. 1994. "Scale Economies and the Volume of Trade." Review of Economics and Statistics 76 (May): 321-328.

Helpman, Elhanan, and Paul R. Krugman. 1985. Market Structure and Foreign Trade (Cambridge, MA: MIT).

Jesudason, James V. 1989. Ethnicity and the Economy: The State, Chinese Business, and Multinationals in Malaysia (New York: Oxford).

Jones, Ronald W. 1995. "The Discipline of International Trade." Swiss Journal of Economics and Statistics 131 (September): 273-288. 
Kandori, Michihiro. 1992. "Social Norms and Community Enforcement." Review of Economic Studies 59 (January): 61-80.

Keesing, Donald B. 1988. "The Four Successful Exceptions: Official Export Promotion and Support for Export Marketing in Korea, Hong Kong, Singapore, and Taiwan, China.” UNDP-World Bank Trade Expansion Program Occasional Paper 2.

Kotkin, Joel. 1992. Tribes: How Race, Religion, and Identity Determine Success in the New Global Economy (New York: Random House).

Legros, Patrick and Andrew Newman. 1997. "Matching in Perfect and Imperfect Worlds." Columbia University, mimeo (June).

Linder, Staffan Burenstam. 1961. An Essay on Trade and Transformation (Uppsala:Almqvist and Wiksells).

McCallum, John. 1995. "National Borders Matter: Canada-U. S. Regional Trade Patterns." American Economic Review 85 (June): 615-623.

Miller, Matthew. 1997. "The Asian Connection." San Diego Union-Tribune (June 17): Cl, C4.

Montgomery, James D. 199 1. "Social Networks and Labor-Market Outcomes: Towards an Economic Analysis.” American Economic Review 81 (December): 1408-14 18.

Mortensen, Dale T. 1988. "Matching: Finding a Partner for Life or Otherwise." American Journal of Sociology 94: S215-240.

Murphy, Kevin, Andrei Shleifer, and Robert Vishny. 1989. "Industrialization and the Big Push." Journal of Political Economy 97 (October): 1003-1026.

Nothdurft, William E. 1992. Going Global: How Europe Helps Small Firms Export (Washington, D.C.: Brookings Institution).

Rauch, James E. 1996. "Trade and Networks: An Application to Minority Retail Entrepreneurship.” Russell Sage Foundation Working Paper No. 100 (June).

Redding, Gordon. 1995. "Overseas Chinese Networks: Understanding the Enigma." Long Range Planning 28: 61-69.

Robison, Richard. 1986. Indonesia: The Rise of Capital (London: Allen \& Unwin).

Rodrik, Dani. 1995. "Getting Interventions Right: How South Korea and Taiwan Grew Rich." Economic Policy 20 (April): 55-97. 
Sattinger, Michael. 1993. "Assignment Models of the Distribution of Earnings." Journal of Economic Literature 31 (June): 83 1-880.

Ziesemer, Bemd. 1996. “The Overseas Chinese Empire.” World Press Review 43 (June): 29. 


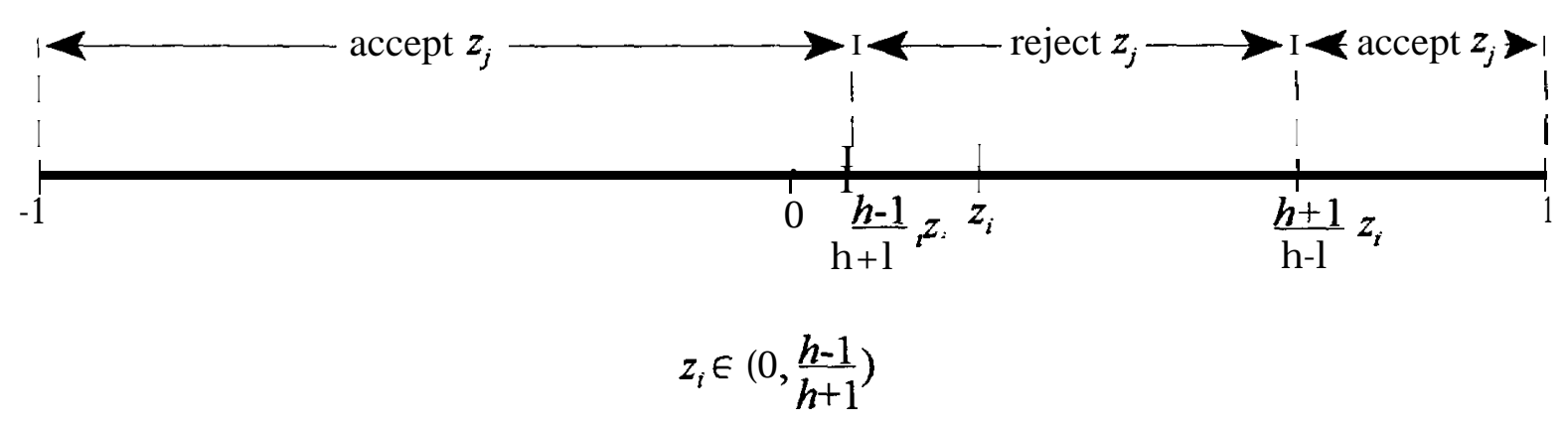

Figure la: Determination of $\mathrm{S}(\mathrm{i})$ in fixed location case

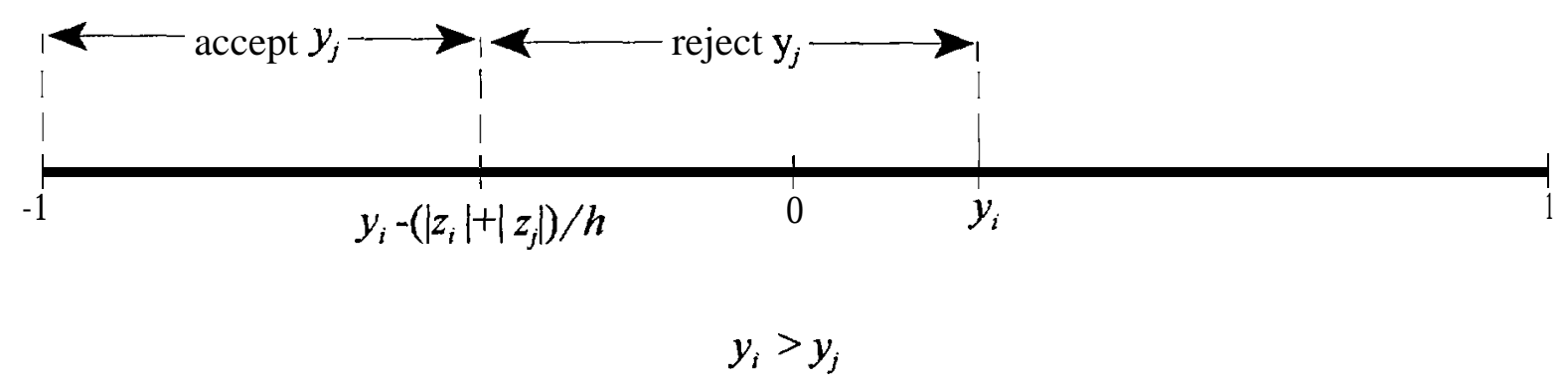

Figure lb: Determination of $S(i)$ in random location case 


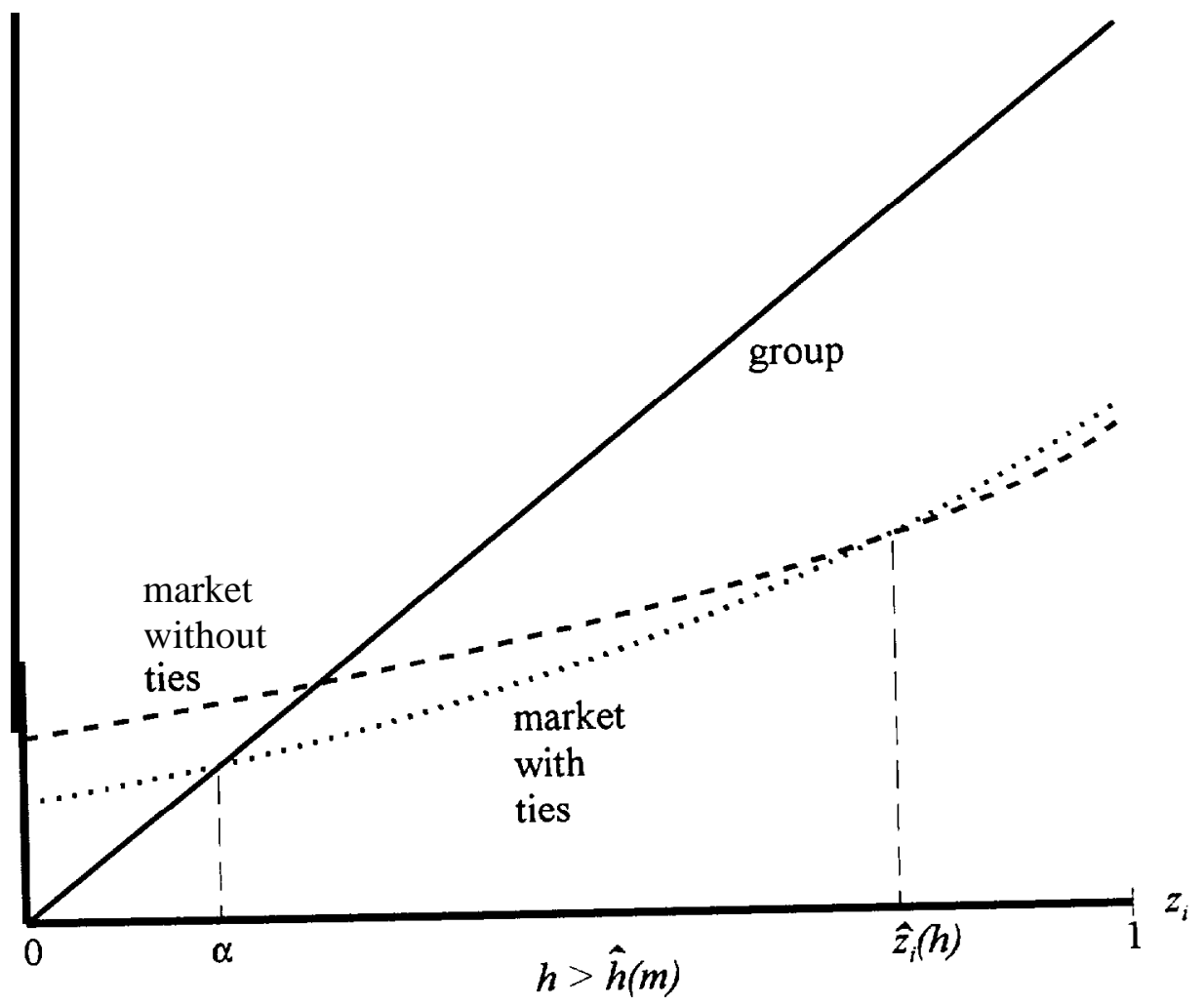

Figure 2a: Expected returns in fixed location case

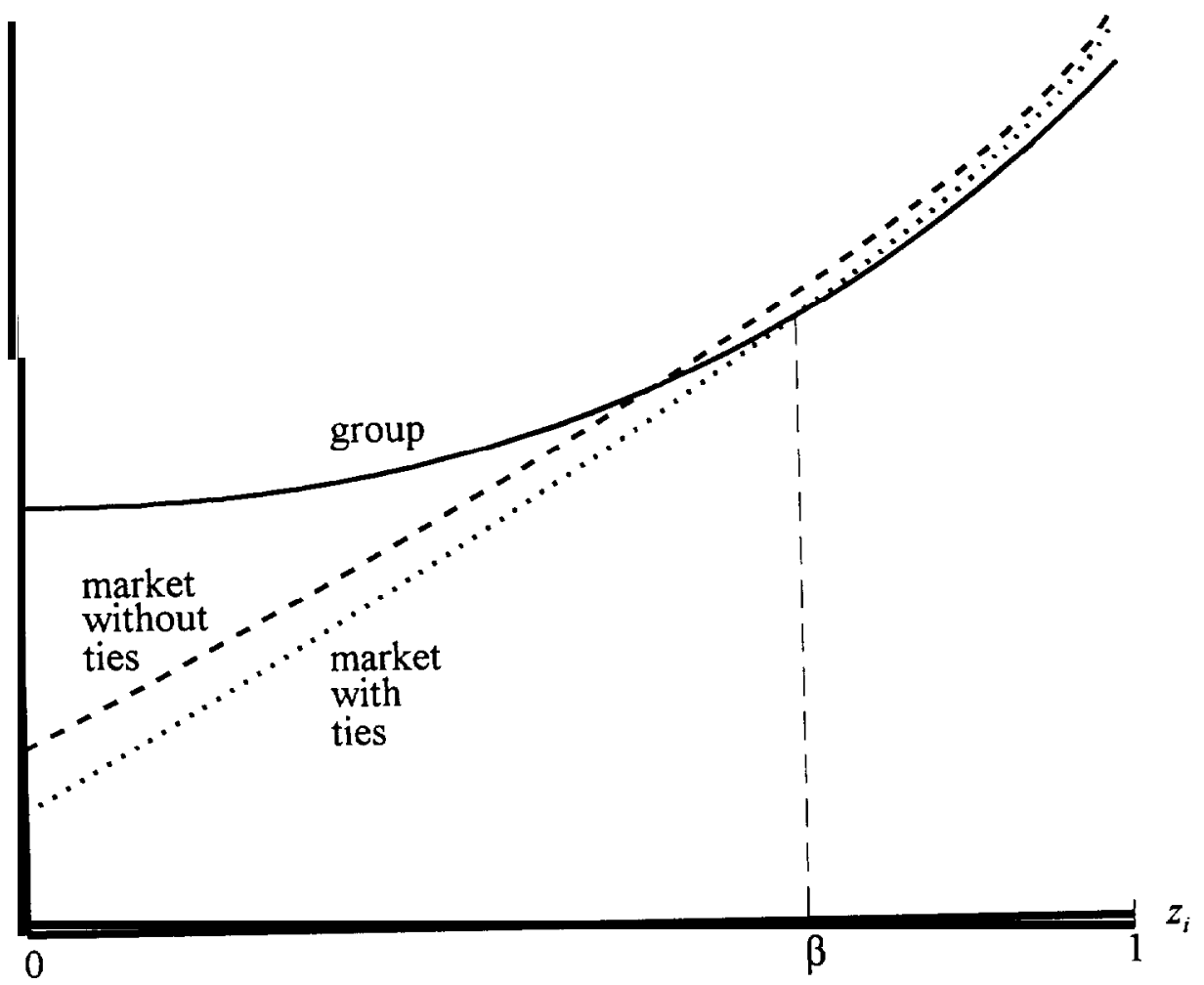

Figure 2b: Expected returns in random location case 


\section{Appendix}

Proof of Proposition 1. We begin by establishing the following Lemma:

Lemma 1. In equilibrium there can be no set of types ofpositive measure who match with partners located on the same side of the median.

Proof of Lemma 1. Suppose this were the case. Then there must be a set of types of equal measure on the opposite side of the median who match among themselves. But then it is always possible to create new partnerships with each member located on a different side of the median such that both partners are at least as well-off. Suppose that typesj and s, on the same side of the median, were matched with each other. Then the maximum possible return toj is $z_{j s}$ when he appropriates the entire return from the partnership, with $z_{j s}<\left\|z_{j}\right\|$. Similarly, if $i$ and $\mathrm{v}$, on the opposite side of the median fromj and s, match among themselves, $i$ can obtain at most $z_{i v}<\left\|z_{i}\right\|$. By matching among themselvesj can earn $\left\|z_{j}\right\|$ and $i$ can earn $\left\|z_{i}\right\|$; each type's return is strictly higher than in the original scenario unless his previous partner was located at the median, in which case the return is unchanged.

Thus in what follows we will ignore the possibility of equilibrium matches occurring between partners on the same side of the median.

We proceed with the proof of Proposition 1.

Suppose first that the the support of the distribution is continuous around the median. Consider types $\mathrm{i}$ and $\mathrm{j}$, on opposite sides of the median. They can always match, produce zij and share it as $\left\|z_{i}\right\|$ to $i$ and $\left\|z_{j}\right\|$ toj. Thus in equilibrium they cannot both earn less. Can at least one of them earn more (for example, can $\mathrm{j}$ earn $\left\|z_{j}\right\|+k$, with $k>0$ )? Only ifj matches with $w$ (on the opposite side of the median) who accepts $\left\|z_{w}\right\|-k\left(\left\|z_{w}\right\| \geq k\right)$. But this can only occur if all types $\mathrm{v}$ on w's side of the median are receiving $\left\|z_{v}\right\|-k$. (Suppose that there exists a $v$ who is matched with $\mathrm{s}$ and receives $\left\|\boldsymbol{z}_{\boldsymbol{v}}\right\|-d, d<k$. Then there exists an $\epsilon>0$ such that w can undercut $\mathrm{v}$, offer $\mathrm{s}$ $\left\|z_{s}\right\|+d+\epsilon$ and be better off.)

But all $\mathrm{v}$ receiving $\left\|z_{v}\right\|-k$ cannot occur in equilibrium because any $\mathrm{v}$ can then match with a type on the same side of the median, but arbitrarily close to it and make both better off. Thus, if the support of the distribution is continuous around the median, the return to $\mathrm{j}$ must equal $\left\|z_{j}\right\|$ and the return to $i\left\|z_{i}\right\|$.

Suppose now that there exists a discrete interval of length $2 A$ in the immediate neighborhood of the median over which the mass of types equals zero. Call $\left\langle z_{i}\right\rangle$ type $i$ 's distance from the mid point of the interval. Each type $i$ on one side of the interval earns individual return $\left\langle z_{i}\right\rangle-k(k \geq 0)$, and each type $\mathrm{j}$ on the opposite side earns $\left\langle z_{j}\right\rangle+k$. Following the logic detailed above, the parameter $k$ must be the same for every type and $k$ must be smaller than $A$ (since underbidding would otherwise be possible), but no profitable deviation exists for all $k \leq A$. 
Similarly the mirror image of this equilibrium $(k<0)$ is also an equilibrium as long as $k \in[-A, 0]$. We can interpret this multiplicity as arising because any point in the interval can be identified as a median. The choice of a median then determines uniquely the entire distribution of returns.

Proof of Corollary 1. Consider a symmetrical equilibrium and suppose that in the domestic market all $z_{i}<0$ receive $\left|z_{i}\right|-k$ and all $z_{i}>0\left|z_{i}\right|+k(k>0)$. By Proposition 1 this can occur only if all types in $[-a, a](a \geq k)$ are absent from the domestic market, i.e., if they are successful with probability 1 in the international market. Consider traders $-a$ and $a$. Since they have the same probability of matching with any foreign type in the international market, and different expected returns in the domestic market, their probabilities of success cannot be equal. If the probability of success is 1 for $\boldsymbol{z}_{\boldsymbol{i}}=-a$, it must be less than 1 for $\boldsymbol{z}_{\boldsymbol{i}}=\boldsymbol{a}$. This establishes the Corollary.

Proof of Corollary 2. Although the two groups of traders restricted to matching with each other are not on opposite sides of the median by assumption (contrary to most standard models), the first part of Proposition 1 remains unchanged: all equilibrium matches must be between individuals on opposite sides of the median. (The argument in Proposition 1 easily generalizes). We analyze separately the two cases of fixed and random location.

(a) Fixed location case. Suppose that in the group all traders from country 1 located to the left of the median receive $h\left|z_{i}\right|+k(k \geq 0)$ when matched with members from country 2 located to the right of the median ( $k$ must be the same for all types to prevent underbidding). In any equilibrium where the distribution of types in the markets (and hence in the group) is symmetrical around the median, it must then be the case that members from country 2 located to the left of the median receive $h\left|z_{i}\right|-k$ when matched with members from country 1 . Any $k$ can now be supported without underbidding, but participation in the group requires that all members be better off than in the domestic equilibrium (notice that in the fixed location case there is no uncertainty). Thus we require $h\left|z_{i}\right|-k \geq\left|z_{i}\right|$ or $k \leq\left|z_{i}\right|(h-1)$ for any $z_{i}$ in the group. If $z_{i}=0$ is among those who use the ties, $k$ must equal zero. Suppose now that individuals in $[-a, a]$ do not use their group ties. Then in a symmetrical equilibrium a must be the same in both countries, and, for a given type, the expected return from entering the international market is equal in both countries. But if $k$ differs from zero, participation in the group is more advantageous for citizens of country 1 than for citizens of country 2 and the threshold $a$ cannot be the same in both countries. It follows that in any symmetrical equilibrium $k$ must equal zero.

(b) Random location case. Suppose that in the group all traders from country 1 who turn out to be to the left of the median receive $h\left|y_{i}\right|+k(k \geq 0)$. All left-hand traders from country 1 attempt to match with right-hand traders from country 2 . For each left-hand individual from country 1 the probability of a lower return than in the domestic market equals the probability that the realized $\left|y_{i}\right|$ is smaller than $\left(\left|z_{i}\right|-k\right) / h$; while for a right-hand individual from country 2 the probability of the same event equals the probability that the realized $\left|y_{i}\right|$ is smaller than $\left(\left|z_{i}\right|+k\right) / h$. It follows that the expected and realized mass of traders who do worse than in the domestic market is larger on the right-hand side for country 2 than on the left-hand side for country 1 . But since the matches have to be pair-wise, in country 1 some of the agents who turn out to be on the 
left-hand side will be rationed out of the group. It is to their advantage to offer to match for $h\left|y_{i}\right|$ $+k$ - e (e in $(O, k])$. Underbidding would continue until the masses of traders who do worse than in the domestic market on the left-hand side of country 1 and the right-hand side of country 2 are equalized, i.e. until $\mathrm{e}=k$, or equivalently until the return to each $y_{i}$ equals $h\left|y_{i}\right|$. But now the same argument must also apply to the right-hand side of country 1 and the left-hand side of country 2 , so returns there must be driven to $h\left|y_{i}\right|$ as well.

Proof of Proposition 2. Observe first that there is always an equilibrium where no-one uses the group ties (since an individual cannot deviate alone). Let us focus instead on the equilibrium with an active group.

(a) Fixed location case. We proceed by steps:

(i) For any $h>1$, all members using their ties is not an equilibrium. Suppose that all members use the ties. Then expected returns in the market are unchanged and are given by equation ( $7 \mathrm{a})$. Consider $z_{i}=0$. His return in the group equals 0 while his expected return in the market equals (h-1)/4. Thus $z_{i}=0$ would deviate to the market.

(ii) For any $h>1$, in any rational expectations equilibrium with an active group, $\left|z_{i}\right|=1$ prefers to use his ties. Consider two types, $z_{i}$ and $z_{s}$, such that $z_{s}>z_{i}$ and $z_{i}>0$. It is not difficult to verify that for any $z_{j}$ (and $\left.h>1\right),\left(r(i, j)-h z_{i}\right)>\left(r(s, j)-h z_{s}\right)$, where $r(i, j)$ is the realized return to $z_{i}$ from matching with $z_{j}$ in the market, and where we need to consider the four possible cases: $z_{j} \in S(i)$, $S(s) ; z_{j} \in S(i), \notin S(s) ; z_{j} \notin S(i), \in S(s) ; z_{j} \notin S(i), \notin S(s)$. Because the inequality holds for any $z_{j}$ it must hold in expected values for any distribution of types in the market. Thus if $z_{i}$ prefers the ties to the market, so does $z_{s}$. By symmetry, the argument can be applied to $z_{i}<0$; thus more generally if $\left|z_{i}\right|$ prefers the ties to the market, so does $\left|z_{s}\right|>\left|z_{i}\right|$. It follows that if any $\left|z_{i}\right|$ matches within the group, so does $\left|z_{i}\right|=1$. To conclude this step of the argument, suppose now that no $\left|z_{i}\right|<1$ were to use the ties. It is easy to verify that given the expectation that the group is not void (and $h>$ 1), $\left|z_{i}\right|=1$ will indeed still prefer to trade through the group, i.e., $h>\operatorname{Er}(1)$, where $\operatorname{Er}(1)$ is given by equation (7a) evaluated at $z_{i}=1$. (Notice that since both $\left|z_{i}\right|=1$ at the two edges of the distribution would prefer the ties, their expectation would be verified.) We can conclude that there cannot be an equilibrium with an active group and $\left|z_{i}\right|=1$ preferring the market.

(iii) Points (i) and (ii) above establish that in any equilibrium with an active group: a) not every member relies on the group; b) $\left|z_{i}\right|=1$ certainly does; c) if $\left|z_{i}\right|$ prefers the ties to the market, so does $\left|z_{s}\right|>\left|z_{i}\right|$. Hence there must exist a positive number $\alpha(h, m)$ such that all members in $[0$, $|\alpha(h, m)|]$ prefer the market, and all members in $(|\alpha(h, m)|, 1]$ prefer the ties. The equilibrium configuration is unique. We show below, when we derive the explicit solution for $\alpha(h, m)$, that $\alpha(h, m)$ itself is unique, concluding the proof of the proposition.

(b) Random location case. It is convenient to begin with the following:

Remark. We first restate the definition of first order stochastic dominance: p.d.f. $f(j)$ f. o. 
stochastically dominates $g(j)$ iff $\int_{-\infty}^{c} f(j) d j<\int_{-\infty}^{c} g(j) d j$. Consider a function $F(i, j), \partial F / \partial j<0 \forall i, j$ $\in[a, b]$. Let $g(j), g^{\prime}(j)$ be p.d.f.s defined over support $[a, b]$, and suppose that $g(j)$ f. o. stochastically dominates $g^{\prime}(j)$. It is easily shown that $Q(i)=\int_{a}^{b} F(i, j) g(j) d j<Q^{\prime}(i)=\int_{a}^{b} F(i, j) g^{\prime}(j) d j$ $\forall i \in[a, b]$. Next, consider a p.d.f. $f(j)$ of traders in the international market in $\boldsymbol{z}_{j}$ space, i.e., defined by their identity in the domestic market.. Since we consider only symmetric equilibria, we define $f(j)$ over the support $[0,1]$ without loss of generality. Now suppose that in our model group members in one or more intervals enter the market. The resulting p.d.f. will f. o. stochastically dominate (be f. o. stochastically dominated by) the p.d.f. in which an equal total mass of coethnics enters the market from the lower (upper) bound of the support. But note that the former (latter) p.d.f. is given by equation (10) for the correct value of $\alpha(\beta)$, where we reserve the notation $\alpha(h, m)$ and $\beta(h, m)$ for the equilibrium values of $\alpha$ and $\beta$. Finally, it is clear from (10) that for given $\alpha(\beta) m>m$ 'implies $f(j)$ is f. o. stochastically dominated by (f. o. stochastically dominates $) f^{\prime}(j)$. It will thus prove useful to define $f^{\alpha}(j)$ and $f^{\beta}(j)$ as the sets of p.d.f.s given by (10) and $m=1$ (its maximum value), where $\alpha, \beta \in(0,1)$. Note that these p.d.f.s respectively are $f$. o. stochastically dominated by and f. o. stochastically dominate the uniform p.d.f. on $[0,1]$.

We continue with the proof

Define $G(i, j) \equiv \operatorname{Er}^{G}(i)-\operatorname{Er}(i j)$, where $E r^{G}(i)$ equals agent $i$ 's expected return to matching in the group and is given by (A5b) and $\operatorname{Er}(i j)$ equals expected market return to agent $i$ from a match with agent $\mathrm{j}$ and is computed in (A3b). It is easily shown that for $h \geq \underline{h}, 1<\underline{h}<\bar{h}, G(i, j)$ is monotonically declining in $z_{i} \in[0,1]$ for all $z_{j} \in[0,1]$. Now define $E r^{M}(i) \equiv \int_{0}^{1} E r(i, j) f^{\prime}(j) d j$ to be the expected market return to agent $i$ given p.d.f. $f^{\prime}(j)$ for market traders. For any $f^{\prime}(j), E r^{G}(i)-$ $\operatorname{Er}^{M^{\prime}}(i)$ inherits the monotonicity of $G(i, j)$ in $z_{i} \in[0,1]$. Thus we have shown that, for $h \geq \underline{h}$, in equilibrium if any coethnic agent $i$ chooses to enter the market, so must all agents $k,\left|z_{k}\right|>\left|z_{i}\right|$.

We next show that some members always choose to use their ties for $h \geq 1$. First, it is easily shown that $\partial \operatorname{Er}(i j) / \partial z_{j}<0$ for all $z_{i}, z_{j} \in[0,1]$. The intuition is that $z_{j}$ is the threat point of your match partner. Now define $E r^{M \alpha}(i) \equiv \int_{0}^{1} E r(i, j) f^{\alpha}(j) d j$. It follows from results 2 and 3 above that $E r^{M \alpha}(i)$ gives the best possible expected market returns to agent $i$, parameterized by $\alpha$ (and $h)$. It is then straightforward to show that there exists a $\underline{z}_{i}>0$ such that all member agents $\left|z_{k}\right| \leq \underline{z}_{i}$ always choose to use their ties; i.e., that $E r^{G}(i)-E r^{M \alpha}(i)>0$ for $h \geq 1, \alpha \in(0,1)$.

It follows from the results in the preceding two paragraphs that when $h \geq \underline{h}$, if some member agents choose to enter the market the p.d.f. $f^{\prime}(j)$ f. o. stochastically dominates the uniform p.d.f. on $[0,1]$, and therefore $\operatorname{Er}^{M^{\prime}}(i)<\operatorname{Er}(i)$ for all $\left|z_{i}\right| \in[0,1]$. Hence if $\operatorname{Er}^{G}(i)-\operatorname{Er}(i)>0$ member agent $i$ uses the ties. Next, it is easily shown that $\partial\left[\operatorname{Er}^{G}(i)-\operatorname{Er}(i)\right] / \partial h>0$ for all $h>\underline{h}, \underline{\underline{h}}$ $<\underline{h}$. Now define $\bar{h}$ implicitly by $\operatorname{Er}^{G}(1)-\operatorname{Er}(1)=0$. It follows that for $h \geq \bar{h}$ the unique equilibrium is for all members to use their ties. It also follows that for $\underline{h}<h<\bar{h}$ the unique equilibrium is for all members $\left|z_{i}\right| \in[\beta(h, m), 1]$ to enter the market and all other members to use their ties, where $\beta(h, m)$ is determined by equation (11 b). We know that $\beta(h, m)<1$ because as $\beta$ $\rightarrow 1, \operatorname{Er}^{M}(i) \rightarrow \operatorname{Er}(i)$, hence $\operatorname{Er}^{G}(\beta)-\operatorname{Er}^{M}(\beta)<0$ for $\beta=1$, contradicting the definition of $\beta(h, m)$. 
We now complete the proof for the case $h<\underline{h}$. It can be shown that the demonstration that $G(i, j)$ is monotonically declining fails for $z_{i} \in\left[z_{i}(h), 1\right]$, where $z_{i}(h)$ is strictly increasing, $z_{i}(\underline{h})=$ 1 , and $z_{i}(1)>\underline{z}_{i}$. It is thus sufficient to show that all member agents $\left|z_{i}\right| \in\left[z_{i}(h), 1\right]$ always prefer the market. But this only requires $\operatorname{Er}^{G}(i)-\operatorname{Er}^{M / \beta}(i)<0$, where $\operatorname{Er}^{M \beta}(i) \equiv \int_{0}^{1} \operatorname{Er}(i, j) f^{\beta}(j) d j$ and we can restrict $\beta$ to the interval $\left[\underline{z}_{i}, 1\right]$. It is straightfonvard to verify that this inequality holds for $z_{i} \epsilon$ $\left[z_{i}(h), 1\right]$.

We show that $\beta(h, m)$ is uniquely determined in the proof of Proposition 3, where this property is needed to establish comparative statics results.

Explicit equations. We report here for completeness the explicit equations for expected returns, in the two cases of trade without group ties and in the presence of ties.

(a) Trade without group ties. Using the notation $f \equiv(h-1) /(h+1)$, in the fixed location case, given (2a') and the uniform distribution, equation (7a) becomes:

$$
\begin{aligned}
\operatorname{Er}(i)= & 1 / 2\left[\frac{h-1}{2}\left(z_{i}+1 / 2\right)+z_{i}\right]+1 / 2\left[f z_{i}^{2}\left(\frac{h+1}{2}\right)\right](1-f / 2) \\
& +1 / 2\left(1-f z_{i}\right)\left(\frac{h-1}{2}\right)\left[1 / 2\left(1+z_{i} / f\right)-z_{i}\right]+1 / 2(1 / f-f) z_{i}^{2}
\end{aligned}
$$

for $z_{i} \in[0, f]$, and

$\operatorname{Er}(i)=1 / 2\left[\frac{h-1}{2}\left(z_{i}+1 / 2\right)+z_{i}\right]+1 / 2\left[f z_{i}^{2}\left(\frac{h+1}{2}\right)\right](1-f / 2)+1 / 2\left(1-f z_{i}\right) z_{i}$

for $z_{i}>f$.

The first term in (Ala) is the expected return from matching with $z_{j}<0$; the second term refers to matches with $z_{j} \in\left[0, f z_{i}\right]$; the third term to matches with $z_{j} \in\left[z_{i} / f, 1\right]$, and the final term to the failed partnerships with $z_{j} \in\left(f z_{i}, z_{i} / f\right)$. Equation (A2a) reflects the fact that for $z_{i}>f$, all matches with $z_{j}>f z_{i}$ fall.

Equations (Ala) and (A2a) simplify to:

$$
\begin{array}{ll}
\operatorname{Er}(i)=\frac{1}{4}\left[(h-1)+2 z_{i}+z_{i}^{2} h\left(\frac{3+h^{2}}{h^{2}-1}\right)\right] & z_{i} \in[0, f] \\
\operatorname{Er}(i)=\frac{h-1}{8}\left[1+2 z_{i}\left(\frac{3+h}{h-1}\right)+z_{i}^{2}\left(\frac{h-1}{h+1}\right)\right] \quad z_{i}>f
\end{array}
$$


Integrating (Ala') and (A2a') over the appropriate intervals (and multiplying by two), we obtain the expression for expected GDP in the text (equation 9a).

In the random location case, it proves useful to rederive equation $\left(3 b^{\prime}\right)$ for $p(i)$ before deriving the explicit equation for $\operatorname{Er}(i)$. Recall that we have four random variables, $y_{i}, y_{j} z_{i}$, and $\boldsymbol{z}_{\boldsymbol{j}}$, i.i.d. uniformly on $[-1,1]$. We wish to compute the probability of the event $h\left|y_{i}-y_{j}\right| \geq\left|z_{i}\right|+\left|z_{j}\right|, h$ $\geq 1$, for a given realization of $z_{i}$. Our solution strategy is to consider only the case $y_{i}>y_{j}$, and multiply by 2 , and then let $z_{j}$ vary only over $[0,1]$, and multiply by 2 again. We have

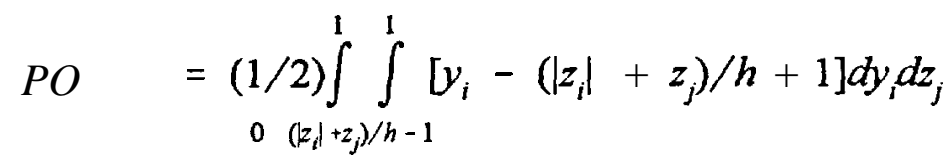

Evaluation of equation (Alb) yields equation (3b').

Continuing to consider only the case $y_{i}>y_{j}$ and letting $z_{j}$ vary only over $[0,1]$, we compute the expected return to agent $i$, where he receives $\left[h\left(y_{i}-y_{j}\right)+\left|z_{i}\right|-z_{j}\right] / 2$ if the above event occurs and $\left|z_{i}\right|$ otherwise. Our solution strategy is to compute the expected return over the range of realizations for which the event occurs, and then add to it $[1-p(i)]\left|z_{i}\right|$. We have

$\operatorname{Er}(i)=(1 / 4) \int_{0}^{1} \int_{\left(z_{j} \mid+z_{j}\right) / h-1}^{1} \int_{-1}^{y_{i}-\left(\left|z_{i}\right|+z_{j}\right) / h}\left[h\left(y_{i}-y_{j}\right)+\left|z_{i}\right|-z_{j}\right] d y_{j} d y_{i} d z_{j}+[1-p(i)]\left|z_{i}\right|$.

Evaluation of equation (A2b), easily done using Mathematica, yields a cubic in $\left|z_{i}\right|$ that is available on request.

(b) Trade with group ties

i) Fixed location case. In the fixed location case, Proposition 2 establishes that the distribution of traders in the anonymous international market is not uniform any longer: because only member traders in the interval $[-\alpha, \alpha]$ enter the market, the density of types must be higher in that interval. Equation (10) reports the two densities. In writing expected returns, we must divide the support so that for all types in a given subinterval the lowest successful partner falls in an interval of equal density (and similarly for the largest one). Consider $z_{i}>0$. Call $z_{f}(i)<z_{i}$ the partner type such that all matches with $z_{j} \leq z_{j}(i)$ are successful, and Z,(j) the type such that all matches $\boldsymbol{z}_{j} \geq Z(\mathrm{i})$ are successful. Both $\boldsymbol{z}_{\boldsymbol{j}}(\boldsymbol{i})$ and $\mathrm{Z}(\mathrm{i})$ can be larger or smaller than $\alpha$; in addition $Z_{j}(i)$ could be larger than 1 (if all matches with $z_{j}>z_{i}$ fail). Thus there are five possible combinations, identifying five relevant segments. A segment will include all $z_{i}$ 's such that (1) z.(i) $\leq a, Z(i) \leq a$; (2), $z$.(i) $\leq \alpha, Z$.(i) $\in[\alpha, 1]$; (3), z(i) $\leq \alpha$, Z.(i) $>1$; (4) $\vec{z}(i) \in(a, 1], Z .(j),>1 ; \overrightarrow{(5)}, z .(j) \in(\alpha, 1] . Z(i), \in[\alpha, \overrightarrow{1}]$. Which' of these five combinations are possible at the same time depends on the relationship between $\alpha$ and $f$ in equilibrium. There are three different regimes, as shown in Figure A: 
a) $\alpha>f$.

The condition. $\boldsymbol{z}_{\boldsymbol{j}}(i) \in(\mathrm{a}, 1]$ identifies a segment where all $\boldsymbol{z}_{\boldsymbol{i}}$ 's satisfy: $f z_{i}>$ a, or $z_{i}>\alpha / f$. If a $>$ f, this requires $z_{i}>1$, which is outside the support. Thus in this regime there are only three segments, defined by conditions (1) to (3) above. Respectively: (1) $\boldsymbol{z}_{i} \in[0, \alpha f]$; (2) $z_{i} \in(\alpha f, f] ;(3) z_{i} \in(f, 1]$.

b) $\alpha \in\left[f^{2}, f\right]$.

The condition Z,(i) $\in[a, 1]$ requires $z_{i} / f<1$ or $z_{i}<f$, while $z_{f}(i) \in(a, 1]$ requires $z_{i}>$ a/' Together they imply $f>\mathrm{a} /$, , or a $<f^{2}$, impossible in this regime. Thus condition (5) above is impossible here, and four segments are relevant, defined by conditions (1) to (4).

Respectively: (1) $z_{i} \in[0, \alpha f] ;(2) z_{i} \in(\alpha f, f] ;(3) z_{i} \in(f, \alpha / f] ;(4) z_{i} \in(a / f, 1]$.

c) $\alpha<f^{2}$.

The condition $z_{(i)} \leq$ a requires $z_{i} \leq a /$ ' while $Z,(i)>1$ requires $z_{i}>f$. Together they imply a $>f^{2}$, impossible in this regime. Thus condition (3) above is impossible here and four segments are relevant, defined by conditions (1),(2), (5) and (4). Respectively:

(1) $z_{i} \in[0, \alpha f]$; (2) $z_{i} \in(\alpha f, \alpha / f]$; (5) $z_{i} \in(\alpha / f, f]$; (4) $z_{i} \in(f, 1]$.

Call $E r 1^{M}(i)$ the expected return of a trader belonging to segment (1) (and similarly below for segments (2), (3), (4), and (5)). Then, taking into account equation (10) and using the notation $2-m(1-a) \equiv d$, we obtain:

$$
\begin{aligned}
\operatorname{Erl}^{M}(i)= & \left.\frac{(1-\alpha)(2-m)\left[h\left[z_{i}+(1+\alpha) / 2\right]+z_{i}-(1-\alpha) / 2\right.}{2 d}\right] \frac{\alpha}{d}\left[\frac{h\left(z_{i}+\alpha / 2\right)+z_{i}-\alpha / 2}{2}\right]+ \\
& \left.\frac{(1-\alpha)(2-m)\left[h\left[(1+\alpha) / 2-z_{i}\right]+z_{i}-(1+\alpha) / 2\right.}{2}\right]+\frac{f z_{i}}{d}\left[\frac{(h+1)\left[z_{i}-\left(f z_{i}\right) / 2\right]}{2}+\right. \\
& \left.\frac{\alpha-z_{i} / f\left[h\left[\left(\alpha+z_{i} / f\right) / 2-z_{i}\right]+z_{i}-\left(\alpha+z_{i} / f\right) / 2\right.}{2}\right]+\frac{z_{i}^{2}(1 / f-f)}{d}
\end{aligned}
$$

for $z_{i} \in[0, \alpha f]$.

The first line refers to matches with $z_{j}<0$, in the two cases of $z_{j}<$-a (hence $z_{j}$ in a low density interval)-- the first term-- and $z_{j} \in[-\mathrm{a}, 0)$, or $z_{j}$ in a high density interval-- the second term. Similarly, the third term captures the expected return from matches with $z_{j}>a$ (low density); the fourth term, matches with $z_{j} \in\left[0, f z_{i}\right]$ (high density); the fifth term, matches with $z_{j} \in\left[z_{i} / f\right.$, a] (high density); and the sixth term, matches with $z_{j} \in\left(f z_{i}, z_{i} / f\right)$ (high density). Only in this last case does a match fail, Although cumbersome, the equation is straightfonvard.

For the other segments, 


$$
\begin{aligned}
& \begin{aligned}
\operatorname{Er}^{M}(i)= & \frac{(1-\alpha)(2-m)}{2 d}\left[\frac{h\left[z_{i}+(1+\alpha) / 2\right]+z_{i}-(1-\mathbf{a}) / 2}{2}\right] \frac{\alpha}{d}\left[\frac{2\left(z_{i}+\alpha / 2\right)+z_{i}-a / 2}{2} \mid+\right. \\
& \frac{\left(1-z_{i} / f\right)(2-m)}{2 d}\left[\frac{(\mathrm{h}-1)\left[\left(1+z_{i} / f\right) / 2-z_{i}\right]}{2}\right] \frac{f z_{i}}{d}\left[\frac{(h|l|)\left[z_{i}-\left(f z_{i} / 2\right]\right.}{2}\right] \mid
\end{aligned} \\
& \frac{a-f z_{i}}{d} z_{i}+\frac{\left(z_{i} / f-\alpha\right)(2-m)}{2 d} z_{i}
\end{aligned}
$$

viii

(A4a)

for $z_{i} \in[\alpha f, \min [f, \alpha / f])$.

$$
\begin{aligned}
E r 3^{M}(i)= & \frac{(1-\alpha)(2-m)}{2 d}\left[\frac{h\left[z_{i}+(1+\alpha) / 2\right]+z_{i}-(1-\alpha) / 2}{2}\right]+\frac{\alpha}{d}\left[\frac{h\left(z_{i}+\alpha / 2\right)+z_{i}-\alpha / 2}{2}\right]+ \\
& \frac{f z_{i}}{d}\left[\frac{(h+1)\left[z_{i}-\left(f z_{i}\right) / 2\right]}{2}\right]+\frac{\partial-f z_{i}}{d} z_{i}+\frac{(1-\alpha)(2-m)}{2 d} z_{i}
\end{aligned}
$$

for $z_{i} \in[f, \min [\alpha / f, 1]$.

$$
\begin{aligned}
\operatorname{Er} 4^{M}(i)= & \left.\frac{(1-a)(2-m)\left[h\left[z_{i}+(1+\alpha) / 2\right]+z_{i}-(1-a) / 2\right.}{2 d}\right]+\frac{\alpha}{d}\left[\frac{h\left(z_{i}+a / 2\right)+z_{i}-a / 2}{2}\right]+ \\
& \left.\frac{\alpha}{d}\left[\frac{(h+1)\left[z_{i}-\alpha / 2\right]}{2}\right]+\frac{\left(f z_{i}-\alpha\right)(2-m)\left[(h+1)\left[z_{i}-\left(f z_{i}+\alpha\right) / 2\right]\right.}{2 d}\right]+ \\
& \frac{\left(1-f z_{i}\right)(2-m)}{2 d} z_{i}
\end{aligned}
$$

for $z_{i} \in(\max [\alpha / f, f], 1]$.

$$
\begin{aligned}
& \operatorname{Er}^{M}(i)=\frac{(1-\alpha)(2-m)}{2 d}\left[\frac{h\left[z_{i}+(1+\alpha) / 2\right]+z_{i}-(1-a) / 2}{2}\right] \frac{\alpha}{d}\left[\frac{h\left[z_{i}+a / 2\right)+z_{i}-a / 2}{2}\right]+
\end{aligned}
$$

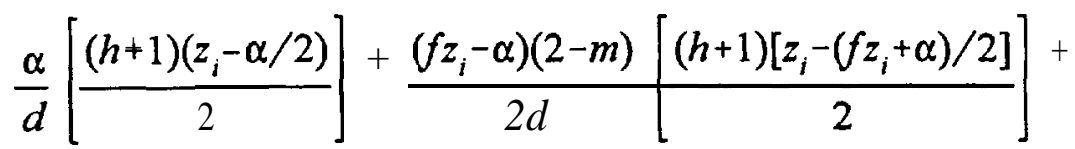

$$
\begin{aligned}
& \begin{array}{c|c}
\left(1-z_{i} / f\right)(2-m) & (h-1)\left[\left(z_{i} / f+1\right) / 2-z_{i}\right] \\
\hline 2 d & 2
\end{array}+\frac{(1 / f-f)(2-m)}{2 d} z_{i}^{2}
\end{aligned}
$$

for $z_{i} \in(\alpha / f, f]$, when $a<f^{2}$, in regime (c).

The equilibrium condition defining a differs in the different regimes. If $a$ is larger than $f$, (regime (a)), then $a$ solves $\operatorname{Er} 3^{M}(\alpha)=h a$. If $a$ instead is smaller than $f$ (regimes (b) and (c)), then $a$ solves $\operatorname{Er} 2^{\mathcal{M}}(\alpha)=h a$. Manipulating the relevant equations, we find: 


$$
\alpha_{3}= \begin{cases}1 / 6 & \text { ifm }=\frac{2(h-1)}{5(h+1)} \\ -3(1+h)(2-m)+2 \frac{\sqrt{(h+1)(2-m)(5+4 h-m(h+1))}}{5 m(h+1)-2(h-1)} & \text { otherwise }\end{cases}
$$

$$
\alpha_{2}=\left\{\begin{array}{lr}
\frac{h-1}{2(2 h-1)} & \text { if } 2 h\left(3+h^{2}\right)=m\left(3+3 h^{3}-h-h^{2}\right) \\
(h-1) \frac{(2-m)(h+1)(2 h-1)-\sqrt{(h+1)(2-m)\left[2+\left(h^{2}-2\right)(6 h-m(h+1))\right]}}{2 h\left(3+h^{2}\right)-m\left(3+3 h^{2}-h-h^{2}\right)} & \text { otherwise }
\end{array}\right.
$$

where the subscript indicates the segment in which $\alpha$ falls.

Both expressions are roots of quadratic equations, but in both cases the root to be chosen is determined uniquely given the requirements: $a \in(0,1), \boldsymbol{\alpha}_{3}>\boldsymbol{f}, \boldsymbol{\alpha}_{2}<f$, and $h \in(1,2]$. Notice that $a$, is defined only for values of $h$ and $m$ such that the argument of the square root is positive -- however, as shown below, this constraint is never binding.

When is $a$ given by $\alpha_{2}$, and when by $\alpha_{3}$ ? The following Proposition answers the question.

Proposition Al. For each $\mathrm{m} \epsilon(0,1]$, there exists a value $\mathrm{h}(\mathrm{m})$ strictly decreasing in $\mathrm{m}$, such that $a=a$, for all $\mathrm{h} \hat{\mathrm{h}}(\mathrm{m})$, and $a=\alpha_{2}$ for all $\mathrm{h} \geq \hat{\mathrm{h}}(\mathrm{m})$.

Proof of Proposition Al. We need to begin by establishing the following lemma:

Lemma 2. For all values of $\mathrm{h} \in(1,2]$ and $\mathrm{m} \in(0,2]$ such that they are well defined, and $\alpha_{3}$ are declining in $m$.

Proof of Lemma 2. We need to find the appropriate sufficient conditions that allow us to sign the derivatives of (A8a) and (A9a) with respect to $m$. The details are available upon request, but the logical steps are the following: 1 . In the case of a, it is possible to show $d^{2} \alpha_{3} / d m d h>0$ over the relevant range of parameters (unless $\alpha_{3}=1 / 6$ ). Hence $d \alpha_{3} / d m$ reaches a maximum at $h=2$. The sign of $d \alpha_{3} / d m$ evaluated at $h=2$ depends on the sign of an expression that has a unique maximum, in the relevant range, at $m=2 / 15$, where it equals zero. Thus $d \alpha_{3} / d m<0$ for all values of a,. 2. In the case of $a$, it is convenient to rewrite a, as a function of $(2-m)$. It is then possible to show that the sign of $d \alpha_{2} / d(2-m)$ depends on the sign of an expression that reaches a maximum when the denominator of (A9a) reaches 1 . Evaluated at the appropriate value of $m$, the expression is negative, guaranteeing that $d \alpha_{2} / d(2-m)$ is negative and hence $d \alpha_{2} / d m$ is positive over the entire admissible range of parameters. 
Consider now the condition $\alpha=f$, where $\alpha_{2}$ and $\boldsymbol{\alpha}_{3}$ are equal. By solving $\operatorname{Er} 3^{M}(i)=h z_{i}$ at $z_{i}=f$ we find that indifference requires:

$\left(3+h-2 h^{2}\right) m=3+6 h-3 h^{2}-2 h^{3}$

(A10a)

where (A10a) is meaningful only for $m \in(0,2]$. When the LHS is larger than the RHS, $\boldsymbol{z}_{\boldsymbol{i}}=\boldsymbol{f}$ prefers the ties. Call $\hat{m}$ the value of $m$ that solves (A10a). It is easy to verify that for all $h \in(1,1.351), \hat{m}$ falls monotonically from 2 to 1 . With $m \leq 1$, Lemma 2 implies that both $a$, and $a$, (if defined) must be larger than $f$; it follows that in this range of $h$ values, for any $m, a$ is given by $a$. At $h=1.4023$, the RHS of (A10a) equals zero, and is negative for larger values of $h$; at $h=1.5$ the LHS of (Al Oa) equals zero, and is negative for larger values of $h$. Finally, for $h$ larger than 1.5 , there is no solution with $\hat{m}<2$. Thus for $h \in(1.4023,2], \boldsymbol{z}_{i}=f$ always prefers the ties to the market. By the proof of Proposition 2 above, this implies $a<f$, or $a$ given by $a$, For $h \in[1.351,1.40231, \hat{m}$ is a declining function of $h$ : the higher is $h$, the smaller is $\hat{m}$, and the larger the set of $m$ values for which $m$ is greater than $\hat{m}$ and $a$ is given by a,. Equivalently, for given $m$, there exists an $\hat{h}(m)$ such that a $=\alpha_{3}$ for all $h \in[1.351, h(m)]$, and $a=\alpha_{2}$ for all $h \in(\hat{h(m)}, 1.40231$, where $h(\hat{m})$ is declining in $m$. Finally, note that at $h \geq 1.351$, the smallest value of $h$ for which $\alpha_{2}$ could be relevant, $a$, is always well-defined.

Indeed it is easy to verify from (A8a) and (A9a) that $h$ ” $(m)$ equals 1.351 when $m=1$; equals 1.382 when $m=0.4$ (the representative value of $m$ used in the numerical examples reported in the text) and approaches 1.4023 when $m$ approaches 0 .

ii) Random location case. In the random location case, equation (A2b) is still correct when $h \geq \bar{h}$. For $h<\bar{h}$, the density of $z_{j}$ is no longer uniform but is instead described by equation (10). The task of computing the expected return to agent $i$ is greatly simplified, however, by the fact that $z_{j}$ is still distributed independently of $y_{i}$ and $y_{j}$. Note also that the distribution of $z_{j}$ is still symmetric about zero.

It is helpful to begin by substituting (Alb) into (A2b) and rearranging to get the following expression:

$$
\begin{aligned}
\operatorname{Er}(i) & =\int_{0}^{1}\left[(1 / 4) \int_{\left(z_{i} \mid+z_{j}\right) / h-1}^{1} \int_{-1}^{y_{i}-\left(\left|z_{i}\right|+z_{j}\right) / h}\left[h\left(y_{i}-y_{j}\right)+\left|z_{i}\right|-z_{j}\right] d y d y_{i}\right. \\
+ & \left.-(1 / 2) \int_{\left(z_{i} \mid+z_{j}\right) / h-1}^{1}\left[y_{i}-\left(\left|z_{i}\right|+z_{j}\right) / h+1\right] d y_{i}|| z_{j} \mid\right] d z_{j}
\end{aligned}
$$

Let $\operatorname{Er}(i j)$ equal the expression that we integrate over $z_{j}$. Now, instead of integrating over $z_{j}$ from 0 to 1 in $(\mathrm{A} 3 \mathrm{~b})$, we employ the low density in (10) for the interval $[0, \beta]$ and the high density in (10) for the interval $(\beta, 1]$, multiplying each expression in (10) by 2 : 
$\operatorname{Er}^{M}(i)=\frac{2-m}{2-m \beta} \int_{0}^{\beta} \operatorname{Er}(i j) d z_{j}+\frac{2}{2-m \beta} \int_{\beta}^{1} \operatorname{Er}(i j) d z_{j}$

Again, evaluation of equation (A4b), easily done using Mathematica, yields a cubic in $\left|z_{i}\right|$ that is available on request.

To compute the expected return to an agent $i$ who matches within the group, we begin by computing the probability of the event $h\left|y_{i}\right| \geq\left|z_{i}\right|, h \geq 1$, for a given realization of $\boldsymbol{z}_{i}$. This is easily shown to equal $1-\left|z_{i}\right| / h$. We then compute the expected return over the range of realizations for which this event occurs, and add to it $\left[1-\left(1-\left|z_{i}\right| / h\right)\right]\left|z_{i}\right|=\left(z_{i}\right)^{2} / h$. We have

$\int_{z_{i} / / h} h y_{i} d y_{i}+\left(z_{i}\right)^{2} / h=h / 2+\left(z_{i}\right)^{2} /(2 h)$.

Equation (1 lb) is obtained by substituting $\beta$ for $\left|z_{i}\right|$ in both (A4b) and (A5b). In the proofs of Propositions 2 and 3, respectively, it is shown that there is no $\beta \in[0,1]$ that solves this equation for $h>\bar{h}$ and a unique $\beta \in[0,1]$ that solves this equation for $h \leq \bar{h}$.

Proof of Proposition 3. (a) Fixed location case. i) To establish $d \alpha / d h>0$, we need to verify both $d \alpha_{3} / d h>0$ and $d \alpha_{2} / d h>0$ over the relevant range of parameters. The details are available upon request, but the logical steps are the following: in the case of $\alpha_{3}$ it is easier to write $\alpha_{3}$ as a function of $f$. Hence $d \alpha_{3} / d h=\left(d \alpha_{3} / d f\right)(d f / d h)$, or $\operatorname{sign}\left(d \alpha_{3} / d h\right)=\operatorname{sign}\left(d \alpha_{3} / d f\right)$. It is then easy to show that a sufficient condition for $\operatorname{sign}\left(d \alpha_{3} / d f\right)>0$ is: $(18-2 f-13 \mathrm{~m})>0$, which is always satisfied if $h \in(1,2], m \in(0,1]$. In the case of $\alpha_{2}$, it is convenient to recall that $a$, solves $\operatorname{Er} 2^{M}\left(\alpha_{2}\right)=h a$,. Thus $d \alpha_{2} / d h=(a$, $\left.d E r 2^{M}\left(\alpha_{2}\right) / d h\right) /\left(d E r 2^{M}\left(\alpha_{2}\right) / d \alpha_{2}-h\right)$. The denominator is increasing in $a$; ; because it is easily shown to be negative when evaluated at the upper bound $a,=f$, it must be negative for all possible values of $\alpha_{2}$. The numerator is also increasing in a,. Call a* the value of $a$ that solves $a^{*}=d \operatorname{Er} 2^{M}\left(\alpha^{*}\right) / d h$; because a $* \alpha_{2}$ in the admissible range of parameters, the numerator must also be negative for all $a$, Hence $d \alpha_{2} / d h>0$. ii) $d \alpha / d m<0$ is established in Lemma 2 above.

(b) Random location case Define $G(\beta ; h, m) \equiv E r^{G}(\beta ; h)-E r^{M}(\beta ; h, m)$. We begin by demonstrating that there exists a unique $\beta \in(0,1)$ that solves $G(\beta ; h, m)=0$ for given $h \in(1, \bar{h})$ and $m \in(0,1]$. Note that from the proof of Proposition 2 we have $G(0 ; h, m)>0$ and $G(1 ; h, m)<$ 0 . Given continuity, it is then sufficient to show that $\partial^{2} G(\beta ; h, m) / \partial \beta^{2}>0 \forall h \in(1, \bar{h})$ and $m \in$ $(0,1]$, so that the plot of $G(\beta ; h, m)$ against $\beta$ must cross the horizontal axis once and only once. It is straightforward to compute this second derivative and verify that it is always positive.

To establish the comparative static result for $m$, it is sufficient to show that $\partial G(\beta ; h, m) / \partial m>0 \forall h \in(1, \bar{h})$ and $m \in(0,1]$. In the proof of Proposition 2, we noted that for given $\beta$ (and $h$ ) $m>m^{\prime}$ implies the p.d.f. $f(j)$ for market traders f. o. stochastically dominates $f^{\prime}(j)$. It follows that $E^{M}(\beta ; h, m)<E r^{M}(\beta ; h, m)$ and therefore $G(\beta ; h, m)>G(\beta ; h, m)$. 
To establish the comparative static result for $h$, it would be sufficient to show that $\partial G(\beta ; h, m) / \partial h>0 \forall h \in(1, \bar{h})$ and $m \in(0,1]$. However, we can only show that $\partial G(\beta ; h, m) / \partial h>$ 0 for $h \in(\hat{h}, \bar{h}), \hat{h}>1$. For $h \in(1, \hat{h}]$ we can show that $\partial G(\beta ; h, m) / \partial h>0 \forall \beta<\hat{\beta}$. Finally, we can demonstrate that $\beta(h, m)<\hat{\beta}$, so that $\partial G(\beta ; h, m) / \partial h>0$ at the equilibrium $\hat{\beta}$.

Proof of Proposition 4. (a) Eixed location case. To calculate expected GDP, we need to integrate individual expected returns for both members and non-members, but to do so we need first to establish for which parameter values each of the three possible regimes ( $a, b$ or $c$, described above) is relevant. Since $d \alpha_{2} / d m<0$ by Proposition 3, for any $h$, a, is at a minimum at $m=1$. But a, $(m=1)>f^{2}$ for all $h \in(1,2]$; it follows that regime (c) is never realized in the relevant range of parameters. Proposition Al then establishes that for any $m$, the equilibrium regime is (a) for $h<\hat{h}(m)$ (where a $>f$ ), and (b) for $h \geq \hat{h}(m)$ (where a $\leq f$ ). Thus:

$$
E G D P_{N}=(2-m)\left(\int_{0}^{\alpha f} \operatorname{Er} 1^{M}(i) d z_{i}+\int_{\alpha f}^{f} \operatorname{Er} 2^{M}(i) d z_{i}+\int_{f}^{1} \operatorname{Er}^{M}(i) d z_{i}\right) \quad \text { if } h<\hat{h}(m)
$$

$E G D P_{N}=(2-m)\left(\int_{0}^{a f} \operatorname{Er} 1^{M}(i) d z_{i}+\int_{\alpha f}^{f} \operatorname{Er}^{M}(i) d z_{i}+\int_{f}^{\alpha / f} \operatorname{Er}^{M}(i) d z_{i}+\int_{\alpha f f}^{1} \operatorname{Er}^{M}(i) d z_{i}\right) \quad$ if $h \geq \hat{h}(m)$ and

$$
E G D P_{G}=m\left(\int_{0}^{\alpha f} \operatorname{Erl}^{M}(i) d z_{i}+\int_{\alpha_{\alpha f}}^{f_{E r}} 2^{M}(i) d z_{i}+\int_{f}^{\alpha} \operatorname{Er} 3^{M}(i) d z_{i}+\int_{a^{a}}^{1} h z_{i} d z_{i}\right) \quad \text { if } h<\hat{h}(m)
$$

$$
E G D P,=m\left(\int_{0}^{\alpha f} \operatorname{Er}^{M}(i) d z_{i}+\int_{\alpha f}^{\alpha} E r 2^{M}(i) d z_{i}+\int_{\alpha}^{1} h z_{i} d z_{i}\right) \quad \text { if } h \geq \hat{h}(m)
$$

where the subscript $N(\mathrm{G})$ stands for non-members (group members), and expected returns $\operatorname{Er}^{M}(i), \operatorname{Er}^{M}(i), E r 3^{M}(i)$ and $E r 4^{M}(i)$ are given by equations (A3a), (A4a), (A5a) and (A6a). Expected GDP for the economy as a whole is the sum of expected GDP for the two groups.

We can then establish: 1. Expected GDP for group members must increase. Since each member has the option of using the ties:

$$
E G D P,>m\left(\int_{0}^{1} h z_{i} d z_{i}\right)=m(h / 2)>m \frac{h^{3}-1}{3\left(h^{2}-1\right)}
$$

where the last term is expected GDP for the group in the absence of ties (equation 9a in the text, corrected for mass).

2. Expected GDP for non-members must fall. We have calculated the integrals and studied the properties of the resulting function with the help of Mathematica. As expected, $E G D P_{N}$ simplifies to equation 9a in the text if $m=0$ (for any $h$ ), or if a $=1$ (for $h<h$ " $(m)$ ). We 
can establish sufficient conditions guaranteeing that (A12a) is everywhere below (9a) (corrected for mass) for all $m>0, a \in(0,1)$. The details are available upon request, but the logical steps are the following: a) When $h \hat{<} h(m)$, (A12a) is everywhere convex in a ; at $a=f$ (the lower bound of the relevant interval for $a$ ), it is strictly declining in $m$, and thus smaller than (9a) for all $m>0$. Hence for all $m>0, a<1$, it must be smaller than (9a). b) When $h \geq \hat{h(m), ~(A 12 a) ~ i s ~}$ strictly decreasing in $a$, for alla $\in\left[f^{2}, f\right], m \in(0,1]$, and is smaller than (9a) at a $=f^{2}$.

3. Expected GDP for the economy as a whole must rise. a) When $h<\hat{h}(m)$, it is possible to find sufficient conditions guaranteeing that EGDP is strictly decreasing in a, for all $a \in[f, 1], m \in(0,1]$. Hence it has a minimum at $a=1$, where it equals (9a). b) When $h z$ $\hat{h}(m), E G D P$ is strictly concave in $a$ over the relevant range of parameter values. For all $m \in(0,1]$, it is larger than (9a) when evaluated at either extreme $\left(\mathrm{a}=f^{2}, a=f\right)$, hence it must be larger than (9a) everywhere.

To evaluate the welfare effect of the ties on individual types, we must study expected returns for each type in each segment. Manipulating the relevant equations, we can establish: i) $\left.\operatorname{Er} 1^{M}(i)-\operatorname{Er}(i)\right)$ is increasing in $z_{i}$, but always negative at $z_{i}=\alpha f$, the upper bound of the interval. Hence every market trader in $[0, \alpha f]$ is hurt by the ties; because $\operatorname{Er}(i)$ is increasing in $z_{i}$, the percentage loss is smaller the higher the type. ii) $\left(\operatorname{Er} 2^{M}(i)-\operatorname{Er}(i)\right)$ is concave in $z_{i}$ for all $z_{i} \in(\alpha f, f]$, given a $>f^{2}$. Because the expression is increasing at the upper bound of the interval $\left(z_{i}=f\right)$, it must be increasing everywhere. And because the expression is negative at $z_{i}=f$, it must be negative everywhere. Hence every market trader in $(\alpha f, f]$ is hurt by the ties, and the percentage loss is smaller the higher the type. iii) $\left(\operatorname{Er} 3^{M}(i)-\operatorname{Er}(i)\right)$ is increasing in $z_{i}$. If $h<h(m)$ (and thus a $>f$ ), the expression is negative at $z_{i}=1$, and hence negative everywhere. If $h=\hat{h}(m)$, the expression is zero at $\boldsymbol{z}_{i}=1$, and negative everywhere else. If $h>h$ ” $(m)$, the upper bound of the interval is $z_{i}=a / f$, where the expression is always negative. Thus, every trader in $\left(f, \min \left[1, a /{ }^{\prime \prime}\right]\right.$ is hurt by the ties unless $a / f=1$, in which case $z_{i}=1$ is just indifferent. The percentage loss is smaller the higher is the type. iv) $\left(\operatorname{Er} 4^{M}(i)-\operatorname{Er}(i)\right)$ is of interest only if $h>\hat{h}(m)$. The expression is always increasing in $z_{i}$, and for all $h>\hat{h}(m)$, equals zero at $\hat{z}_{i}(h) \in(a / f, 1)$. Once again the percentage loss is smaller the higher the type. All together these observations establish the pattern of individual losses for non-members described in the Proposition.

In the group, all $z_{i} \leq a$ enter the market. The results above show that all of them, including a, must be worse-off (recall that a belongs to segment 3 if $h<\hat{h}(m)$ ), and segment 2 if $h \geq \hat{h}(m)$ ), and that their percentage loss must be declining in $z_{i}$. Among members choosing the group, by continuity types close to a must lose, although a majority must gain given the aggregate gain for the group. It is not difficult to verify that $\left(h z_{i}-\operatorname{Er}(i)\right) /(\operatorname{Er}(i))$ is increasing in $z_{i}$ (for both $z_{i}$ larger and smaller than $f$ ). This establishes the remaining part of the Proposition in the fixed location case.

(b) Random location case. 1 . First consider the case $h \geq \bar{h}$. The argument in the text demonstrates that expected returns to non-members are unaffected. It is then sufficient to demonstrate that expected per capita GDP rises for members: using (A5b) and (9b), we have 
$\int_{0}^{1} E r^{G}(i) d i-E(G D P) / 2=h / 2+1 / 6 h-\left(h / 3+7 / 24 h-1 / 16 h^{2}\right)=h / 6-3 / 24 h+1 / 16 h^{2}>0$. Turning to the case $h<\bar{h}$, expected GDP $=m \int_{0}^{\beta} E r^{G}(i) d i+(2-m) \int_{0}^{\beta} E r^{M}(i) d i+2 \int_{\beta}^{1} E r^{M}(i) d i$.

Subtracting $E(G D P)$, given by $(9 \mathrm{~b})$, yields a relatively simple expression in $h, m$, and $\beta$, which is easily shown to be positive $\forall h \in[1, \bar{h}], m \in(0,1]$, and $\beta \in(0,1]$, and is therefore positive for the equilibrium $\beta(h, m)$.

3.i) For the group, since each member has the option of using the ties the result follows from the preceding paragraph. For non-members, in the proof of Proposition 2 we noted that the p.d.f. described by (10) f. o. stochastically dominates the uniform p.d.f. on $[0,1]$, and therefore $\operatorname{Er}^{M}(i)<\operatorname{Er}(i)$ for all $\left|z_{i}\right| \in[0,1]$.

3.ii)(a) It was shown in the proof of Proposition 2 that the gain in expected returns to members who use the ties is monotonically declining in $\left|z_{i}\right|$. Since $\operatorname{Er}(i)$ is increasing in $\left|z_{i}\right|$ the percentage gain declines even more steeply. Since $\operatorname{Er}^{M}(i)<\operatorname{Er}(i)$, by continuity members near $\beta$ who use the ties must be worse-off. The result for members who join the market follows from the proof of point $3 . \mathrm{ii})(\mathrm{b})$ below.

3.ii)(b) In the proof of point 3.i) we showed that all non-members are worse-off than in the absence of the ties. This resulted from the fact that it is the members with high bargaining power who enter the market, It is easily shown that $\partial^{2} \operatorname{Er}(i j) / \partial z_{j} \partial z_{i}>0$ for all $z_{i}, z_{j} \in[0,1]$ : the degree to which you are hurt by your partner's bargaining power decreases with $\left|z_{i}\right|$. It is then straightforward to demonstrate that the extent to which $\operatorname{Er}^{M}(i)$ is reduced relative to $\operatorname{Er}(i)$ as a result of integrating over a p.d.f. for $z_{j}$ that $f$. o. stochastically dominates the uniform p.d.f. on $[0,1]$ is decreasing in $\left|z_{i}\right|$, i.e., the change in $\operatorname{Er}^{M}(i)-\operatorname{Er}(i)$ w.r.t. $\left|z_{i}\right|$ is positive. Since $\operatorname{Er}(i)$ is increasing in $\left|z_{i}\right|$ the percentage loss declines even more steeply. 
(a)

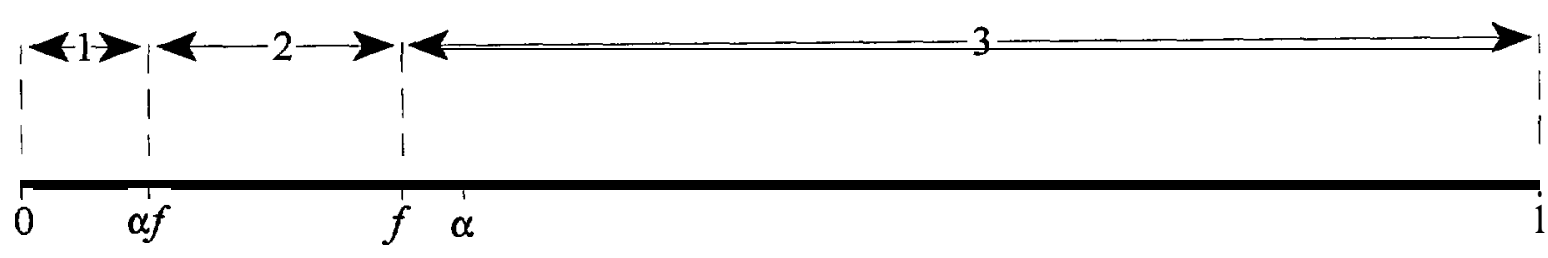

$\alpha>\frac{h-1}{h+1}$

(b)

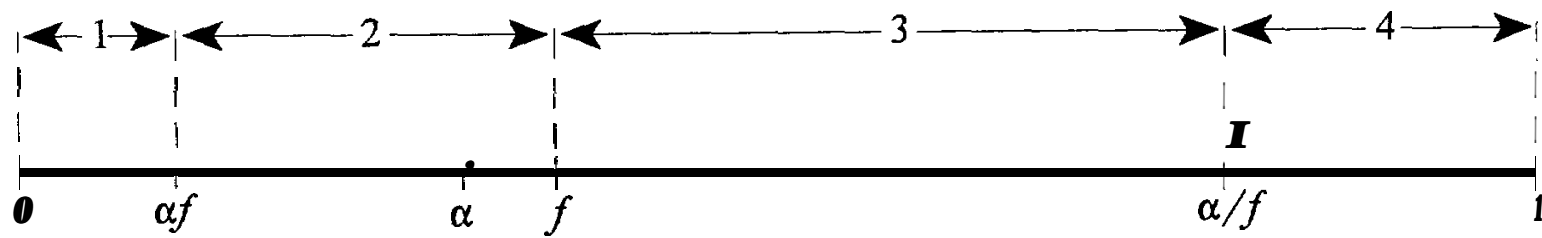

$$
\alpha \in\left[\left(\frac{h-1}{h+1}\right)^{2}, \frac{h-1}{h+1}\right]
$$

(c)

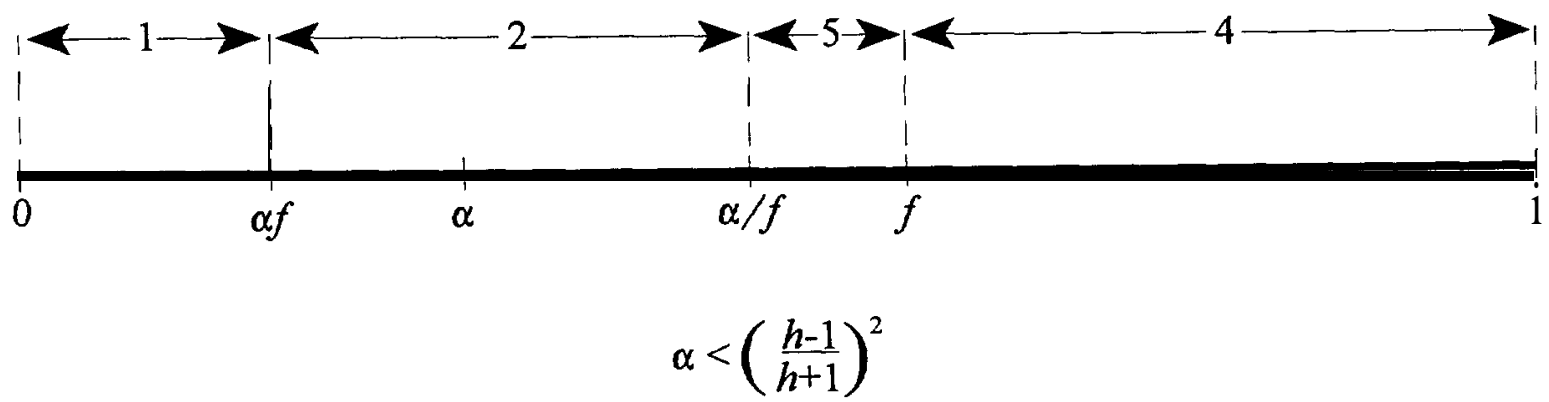

Figure A 